University of Massachusetts Amherst

ScholarWorks@UMass Amherst

Open Access Dissertations

$9-2010$

\title{
The Relationship between Patient Object Relations and The Therapeutic Alliance in a Naturalistic Psychotherapy Sample
}

Paula Andrea Errazuriz Arellano

University of Massachusetts Amherst

Follow this and additional works at: https://scholarworks.umass.edu/open_access_dissertations

Part of the Clinical Psychology Commons

\section{Recommended Citation}

Errazuriz Arellano, Paula Andrea, "The Relationship between Patient Object Relations and The Therapeutic Alliance in a Naturalistic Psychotherapy Sample" (2010). Open Access Dissertations. 254.

https://doi.org/10.7275/1663904 https://scholarworks.umass.edu/open_access_dissertations/254

This Open Access Dissertation is brought to you for free and open access by ScholarWorks@UMass Amherst. It has been accepted for inclusion in Open Access Dissertations by an authorized administrator of ScholarWorks@UMass Amherst. For more information, please contact scholarworks@library.umass.edu. 
THE RELATIONSHIP BETWEEN PATIENT OBJECT RELATIONS

AND THE THERAPEUTIC ALLIANCE IN A

NATURALISTIC PSYCHOTHERAPY SAMPLE

A Dissertation Presented

by

PAULA A. ERRÁZURIZ ARELLANO

Submitted to the Graduate School of the University of Massachusetts Amherst in partial fulfillment of the requirements for the degree of

DOCTOR OF PHILOSOPHY

September 2010

Clinical Psychology 
(C) Copyright by Paula Errázuriz Arellano 2010

All Rights Reserved 


\section{THE RELATIONSHIP BETWEEN PATIENT OBJECT RELATIONS \\ AND THE THERAPEUTIC ALLIANCE IN A \\ NATURALISTIC PSYCHOTHERAPY SAMPLE}

A Dissertation Presented

by

Paula A. Errázuriz Arellano

Approved as to style and content by:

Michael J. Constantino, Chair

Elizabeth Harvey, Member

Ronnie Janoff-Bulman, Member

Lisa A. Keller, Member

Melinda Novak, Department Chair

Psychology Department 


\section{DEDICATION}

Para Esteban, con todo mi amor y admiración 


\section{ACKNOWLEDGEMENTS}

This dissertation would not have been possible without the support and wise guidance of my dissertation chair, Dr. Michael Constantino, my advisor, Dr. Lisa Harvey, and the additional members of my committee, Dr. Ronnie Janoff-Bulman and Dr. Lisa A. Keller. In addition, Dr. Aline Sayer's statistical help was fundamental for the development of this project.

I am grateful for the help of Samantha Perry, Chaya Bekermus, Kristin Iodice, Hannah Hinde, and other research assistants, whose help in data collection and data entry was invaluable, and to the patient staff of the Psychological Services Center at UMASS Amherst and the Danielsen Institute at Boston University. I also wish to express my appreciation to all the patients and therapists who volunteered their participation in this project.

Last but not least, I want to thank my family for providing emotional support even though they live thousands of miles away, and to my husband, Dr. Esteban Calvo, who helped me stay focused, give my best effort, and was my main statistical consultant. 


\author{
ABSTRACT \\ THE RELATIONSHIP BETWEEN PATIENT OBJECT RELATIONS \\ AND THE THERAPEUTIC ALLIANCE IN A \\ NATURALISTIC PSYCHOTHERAPY SAMPLE
}

SEPTEMBER 2010

PAULA A. ERRÁZURIZ ARELLANO

B.A., UNIVERSIDAD CATÓLICA DE CHILE

M.A., BOSTON UNIVERSITY

M.S., UNIVERSITY OF MASSACHUSETTS AMHERST

Ph.D., UNIVERSITY OF MASSACHUSETTS AMHERST

Directed by: Professor Michael J. Constantino

The quality of the patient-therapist relationship, or therapeutic alliance, is widely viewed as an important element of the psychotherapeutic process. Empirically, the therapeutic alliance is a well-established and robust predictor of therapeutic change. With its clear impact on therapeutic success, researchers have increasingly examined factors that contribute to alliance development, including patient psychological characteristics. This study examined the relationship between patients' object relations (i.e., mental representations of self and others) and alliance quality, and whether timing of the alliance rating and the rater perspective (patient vs. therapist) moderated this relationship. Participants were 73 patients and 23 therapists from two outpatient mental health clinics. Patients completed the Bell Object Relations Inventory at baseline, and both patients and 
therapists completed the Working Alliance Inventory across multiple therapy sessions. On average, patients perceived the alliance more positively than their therapists, and there was a small, but statistically significant, correlation between their perspectives. Patients' general object relations deficits, as well as greater alienation and insecure attachment, were associated with more negative patient-rated alliance quality. On the other hand, patients' greater egocentricity was associated with a more positive patient-rated alliance perception. Patients' object relations did not significantly predict therapist-rated alliance, but symptom severity did. Less severe patient symptomatology was associated with more positive therapist alliance perception. Symptom severity did not predict patient-rated alliance. The number of sessions in which patients engaged was positively associated with therapist-rated alliance, while patient-rated alliance remained stable across sessions. Time of the alliance assessment did not moderate the relationship between object relations and either patient- or therapist-rated alliance. The results suggest that it may be important to consider patients' presenting quality of object relations for treatment planning and for negotiating the therapeutic alliance. 


\section{CONTENTS}

Page

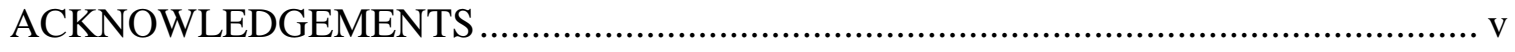

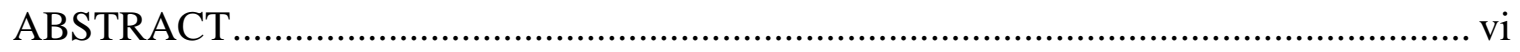

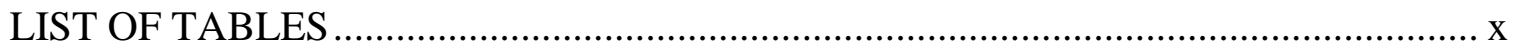

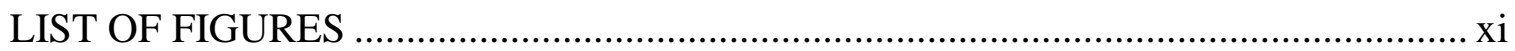

\section{CHAPTER}

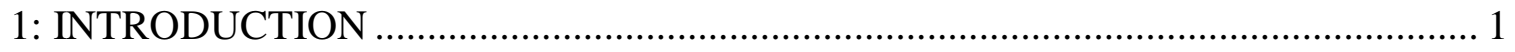

1.1: Predictors of the Therapeutic Alliance .......................................................... 2

1.2: Patients' Object Relations and the Therapeutic Alliance ................................... 3

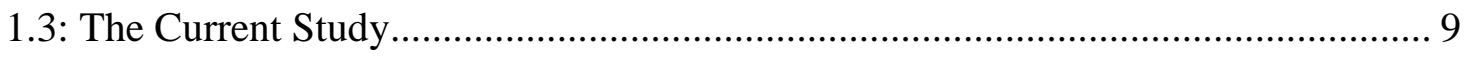

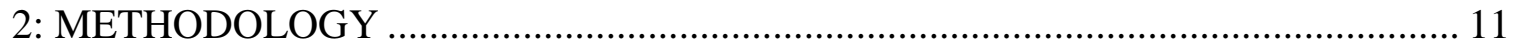

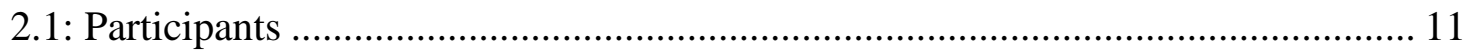

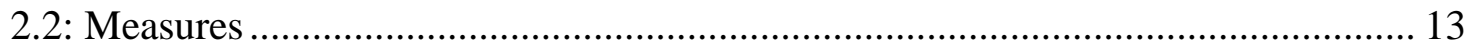

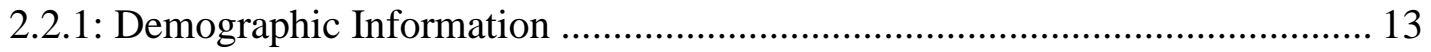

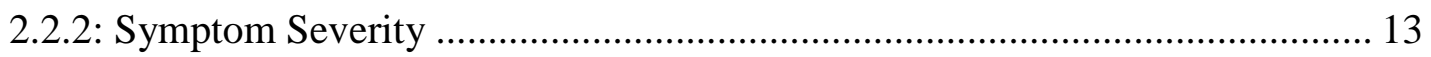

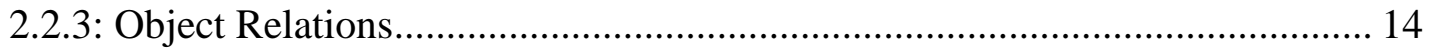

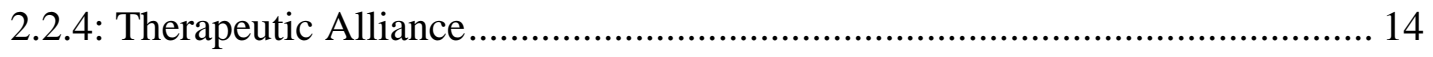

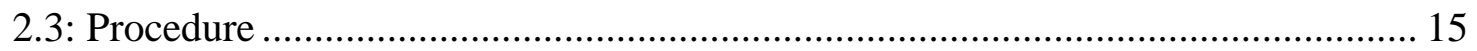

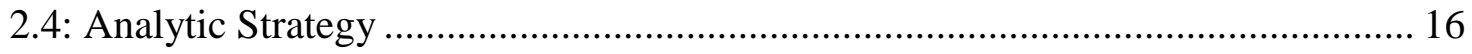

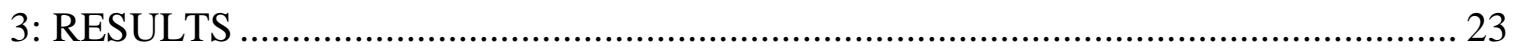

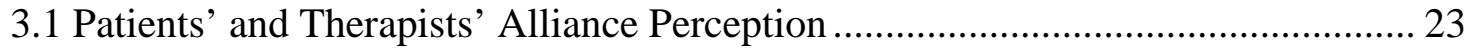


3.2 Predicting Patients' Alliance with General Object Relations

3.3 Predicting Patients' Alliance with Object Relations’ Dimensions 24

3.4 Predicting Therapists' Alliance with General Object Relations .......................... 25

3.5 Predicting Therapists' Alliance with Object Relations' Dimensions .................... 26

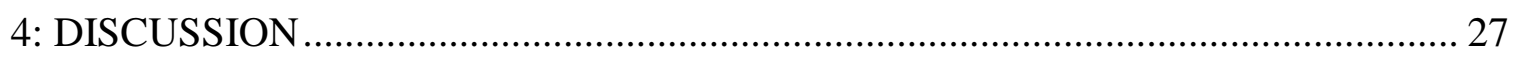

APPENDICES

A: WORKING ALLIANCE INVENTORY (WAI) ........................................... 43

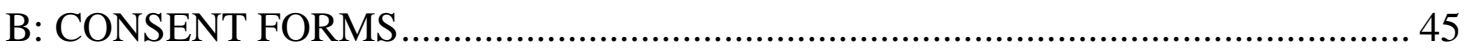

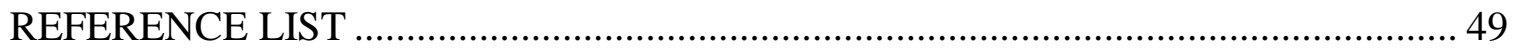




\section{LIST OF TABLES}

Table

Page

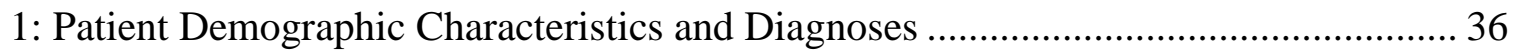

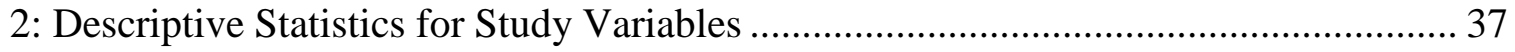

3: Predicting Patients’ Alliance with General Object Relations: Unstandarized

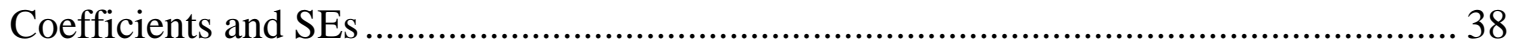

4: Predicting Patients’ Alliance with Object Relations Dimensions: Unstandarized

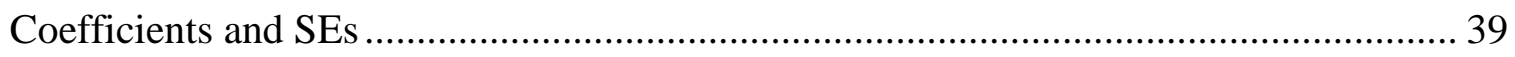

5: Predicting Therapists’ Alliance with General Object Relations: Unstandarized

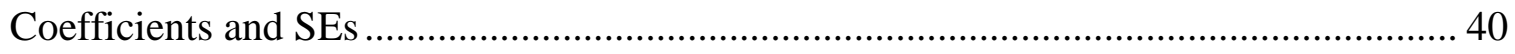

6: Predicting Therapists' Alliance with Object Relations Dimensions: Unstandarized

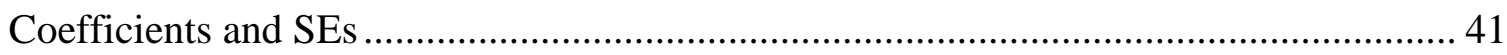




\section{LIST OF FIGURES}

Figure $\quad$ Page

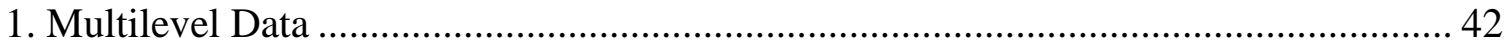




\section{CHAPTER 1}

\section{INTRODUCTION}

The importance of a quality patient-therapist relationship has long been discussed in the psychotherapy literature. Within the psychoanalytic tradition, Freud (1912) emphasized the importance of the analyst and analysand developing a friendly, affectionate, and reality-based attachment that can coexist with the more transferential and interpretable components of the relationship. Years later, Zetzel (1956) introduced the term therapeutic alliance to refer to the patient's positive, non-neurotic attachment to the therapist. Zetzel believed that positive early experiences between caregiver and child influenced the patient's capacity to engage in a stable and trusting relationship with a therapist. Greenson (1965) coined the term working alliance to reflect the patient's capacity to work collaboratively with the therapist on treatment objectives, even in the context of potential transference distortions. Within the patient-centered tradition, Rogers (1957) conceptualized the therapeutic relationship as a set of therapist-offered conditions (i.e., congruency, unconditional positive regard, and empathy) that were at least minimally perceived and experienced by the patient.

Over time, alliance definitions also emerged in orientations outside of psychoanalysis and patient-centered therapy, and the patient-therapist relationship has become widely accepted as a variable important to most, if not all, psychotherapies (Constantino, Castonguay, \& Schut, 2002). In an attempt to generalize the alliance beyond its early psychoanalytic and patient-centered roots, Bordin (1979) proposed a landmark pantheoretical conceptualization. Bordin defined the alliance as having three components: (a) agreement between patient and therapist on the goals of treatment, (b) 
agreement between patient and therapist on the tasks of treatment, and (c) the quality of the patient-therapist emotional bond. Bordin $(1979,1994)$ understood the alliance as a central treatment ingredient that allows the patient to engage genuinely in the therapeutic process and to obtain its benefits. Bordin's alliance definition was further developed by Gaston (1990), who proposed that the alliance is a multidimensional construct consisting of four relatively independent elements: (a) the patient's capacity to work purposefully in therapy, (b) the patient's affective bond with the therapist, (c) the therapist's empathic understanding of and involvement with the patient, and (d) the agreement between patient and therapist on the goals and tasks of treatment.

Empirically, the therapeutic alliance has become the most widely studied aspect of the treatment process across different psychotherapies and psychological conditions (Castonguay, Constantino, \& Holtforth, 2006; Crits-Christoph \& Connolly Gibbons, 2003). Such work has demonstrated that the alliance is positively related to a broad range of treatment outcomes, including symptom reduction, improvement in interpersonal functioning, global ratings of success, and improvement in target complaints (see Constantino et al., 2002; Constantino, Castonguay, Zack, \& DeGeorge, in press; Horvath \& Bedi, 2002 for reviews). Furthermore, the timing of when the alliance is measured appears to have an effect on the relationship between alliance and outcome. In general, the alliance has been found to be a stronger predictor of outcome when measured early in treatment (Horvath \& Bedi, 2002; Horvath \& Symonds, 1991).

\section{1: Predictors of the Therapeutic Alliance}

Given that the alliance is a well-established contributor to treatment outcome, it is important to understand predictors of its development and maintenance (Castonguay et 
al., 2006). The extant literature shows that both therapists and patients contribute to alliance quality and negotiation (see Constantino et al., 2002; Constantino et al., in press). Therapist characteristics, such as being warm, honest, respectful, flexible, supportive, empathic, interested, congruent, and open are associated with a positive alliance (see Ackerman \& Hilsenroth, 2003; Constantino et al., in press). On the other hand, therapist's rigidity, criticalness, inappropriate self-disclosure, and self-directed hostility have been associated with alliance difficulties (see Ackerman \& Hilsenroth, 2001; Constantino et al., in press).

Patient characteristics, both intrapsychic and interpersonal, are also associated with the alliance. At the intrapsychic level, patients' positive expectations for improvement, motivation for treatment, emotional involvement in therapy, and psychological mindedness have been found to relate positively to alliance quality. On the other hand, patients' avoidance, perfectionism, and depressogenic beliefs have been found to relate negatively to alliance quality (see Constantino et al., in press). Interpersonally, patients with more global interpersonal problems have more difficulty developing positive alliances in therapy. More specifically, patients who are overly resistant, cold, hostile, defensive, or negativistic have worse therapy relationships than people who are warmer, more affiliative, and more engaged (see Constantino et al., in press).

\section{2: Patients' Object Relations and the Therapeutic Alliance}

Inasmuch as psychotherapy involves an interpersonal process, it is also reasonable to expect that patients' object relations would have a bearing on the therapeutic relationship (Le Bloc'h, de Roten, Drapeau, \& Despland, 2006). Object relations are 
mental representations of self and others, which appear to originate early in life and influence how one thinks, feels, and acts toward self and others (Blatt, 1974; Bowlby, 1969; Huprich \& Greenberg, 2003; Jacobson, 1964; Kernberg, 1976). According to object relations theory, these mental representations are created in interpersonal transactions that begin with the infant-caregiver relationship, are constructed and revised over the life cycle, and have conscious and unconscious cognitive, affective, and experiential components (Blatt \& Auerbach, 2003; Blatt, Auerbach, \& Aryan, 1998). Object relations are postulated to derive from and, in turn, to determine the experience of the self in an interpersonal environment (Blatt \& Lerner, 1983; Bowlby, 1988; Jacobson, 1964). According to Blatt $(1974,1995)$, key aspects in the development of healthy object relations are: (a) the capacity to establish and maintain a sense of separateness between self and other, (b) the capacity to establish and maintain consistent emotional relationships with significant others, and (c) a consolidated, cohesive, and stable representation of oneself.

According to Bell's (1995) research, object relations' deficits can be grouped into four dimensions: alienation, insecure attachment, egocentricity, and social incompetence. High alienation consists in difficulties trusting others, establishing intimacy in relationships, and connecting emotionally. Persons with insecure attachment are hypersensitive to rejection, easily hurt by others, and desperately seek close relationships. Individuals with high egocentricism tend to perceive others' existence only in relation to themselves, are demanding, manipulative, and controlling. Finally, persons with high social incompetence tend to be shy, socially anxious, and have difficulties making 
friends. According to Bell, difficulties in any of these dimensions pose challenges for the therapeutic relationship.

There is some preliminary evidence that patients' object relations may be an important predictor of the alliance. For example, Piper et al. (1991) examined the quality of patients' object relations in the prediction of the alliance. Of the 64 adult outpatients who received short-term dynamic psychotherapy, half of the sample was classified as having either high or low quality object relations. Patients with high quality of object relations had better alliances with their therapists, as rated by both patients and therapists, than those with low quality objects relations. It is important to note that the generalizability of this finding may be limited by the authors' use of a unique and studyspecific alliance measure.

In a study of 42 adult psychotherapy outpatients in a community mental health clinic, Honig, Farber, and Geller (1997) assessed patients' object relations using the Conceptual Level Scale (Blatt, 1974) at intake and the Therapist Representation Inventory (Geller, Cooley, \& Hartley, 1982), which measures the conscious experiences of the therapist representations, eight to twelve weeks later. Patients with higher levels of object relations engaged with their therapist in the task of self-improvement, while patients with lower levels of object relations related to their therapist in a way that their intrapsychic needs and expressions of anger would be managed, but not in a way that helped work meaningfully toward self-improvement. The findings from this study support the idea that as levels of object relations increase, the capacity to have a more mature representation of the therapist also increases. However, the study did not assess specific alliance components, such as agreement on the goals and tasks of therapy. 
Studies of early memory narratives also suggest that a person's representations of self and others play a significant role in alliance development. For example, PinskerAspen, Stein, and Hilsenroth (2007) found in a sample of 57 patients in psychodynamic psychotherapy at a university-based clinic that those who reported a stronger alliance with their therapist exhibited greater complexity, differentiation, and interrelatedness of self and other in their early memory narratives. This result is consistent with Ryan and Cicchetti's (1985) finding that higher patient alliance ratings were significantly related to object relations, as assessed through patients' narratives in a sample of 40 adults during an initial psychoanalytic psychotherapy interview.

Studies on adult attachment also provide indirect support for a significant relationship between object relations and the alliance. For example, insecure adult attachment has been found to be associated with insecure attachment to one's therapist (e.g. Mallinckrodt, Porter, \& Kivlighan, 2005), and stronger attachment of patients to therapists was found to be associated with a stronger working alliance in long-term psychoanalytic therapy (Parish \& Eagle, 2003). Furthermore, it has been proposed that internalized parental images represent aspects of object relations that have an impact on subsequent capacity for bonding and, thus, for the working alliance (Hersoug, Monsen, Havik, \& Hoglend, 2002). This is consistent with the finding from a study of time-limited dynamic psychotherapy where the quality of patients' early parental experience related positively to the capacity to develop a positive interpersonal process in therapy (Hilliard, Henry, \& Strupp, 2000).

Despite the converging evidence for a positive relationship between object relations and the alliance, Goldman and Anderson (2007) failed to find such a 
relationship. In their study, 30 adult psychotherapy patients from university-based outpatient centers were administered the Revised Adult Attachment Scale (Collins \& Read, 1990) and Bell's Object Relations Reality Testing Inventory (BORRTI; Bell, 1991, 1995) prior to therapy, and completed the Working Alliance Inventory (WAI; Horvath \& Greenberg, 1989) following their first, second, and third sessions. Security of attachment accounted for $15 \%$ of the variance in alliance at session one; an amount that did not increase significantly when adding quality of object relations as a predictor. Furthermore, quality of object relations did not display predictive ability on its own for any of the alliance ratings. However, exploratory correlations revealed a significant negative relationship in session one between the alliance and alienation, a specific dimension of deficit in object relations. No other significant relations were found for other aspects of object relations (insecure attachment, egocentricity, and social isolation) for any of the alliance sessions.

Mallinckrodt et al. (2005) found that social incompetence, an object relations' dimension (assessed with the BORRTI), negatively predicted overall alliance quality (assessed with the WAI) in a sample of 44 female clients. However, the other object relations' dimensions (i.e. alienation, insecure attachment, and egocentricity) failed to predict overall alliance quality in this study.

Finally, Van et al. (2008) examined 81 patients diagnosed with mild to moderately severe depression and treated with short-term psychodynamic therapy. These patients were assessed for object relations functioning using the Developmental Profile (DP; Abraham et al., 2001) and patient alliance was assessed at sessions 8 and 24 with the Helping Alliance Questionnaire (HAq; Luborsky, McLellan, Woody, O’Brien, \& 
Auerbach, 1985). No association was found between object relations and therapeutic alliance during treatment.

From the relatively small array of previous studies, some, but not all, suggest a significant relationship between patient object relations and the therapeutic alliance. However, various shortcomings characterize the empirical literature on the association between object relations and the alliance, including (a) most of the studies that provide evidence for a significant relationship use measures of the alliance and/or object relations that are not well known or are study-specific, making their findings difficult to compare across studies, (b) none of the aforementioned studies controlled for therapist variability, and (c) most of the studies have either the therapist or patient as rater of the alliance, but not both. Thus, further research is needed to clarify the nature of the object relationsalliance link using well-established measures, accounting for therapist differences, and assessing multiple perspectives on the alliance.

Additional research should also explore possible moderators of the object relations-alliance relationship. For example, given that the timing of when the alliance is measured appears to moderate the relationship between alliance and treatment outcome (Horvath \& Bedi, 2002; Horvath \& Symonds, 1991), it seems important to assess if it also moderates the relation between object relations and alliance. For example, if the relationship is stronger at the beginning of treatment rather than later in treatment, it might suggest that patients' object relations have a stronger influence on the burgeoning alliance than the more established alliance. On the other hand, if timing does not moderate the relationship, it would suggest that the influence is more pervasive. 
In addition, who assesses the alliance may also influence the link between object relations and the alliance. Most studies have looked only at the relationship between patient-reported alliance quality and patient object relations. However, studies that have compared patients' and therapists' rating of the alliance have arrived at different conclusions. For example, Dyke (1996) found that patient-rated alliance was uncorrelated with the quality of object relations, while therapist-rated alliance was positively correlated with the quality of object relations. On the other hand, Niemeyer (2005) and Piper et al. (1991) found that both patient and therapist ratings of the alliance were correlated with object relations. Thus, additional research is needed to clarify the impact of perspective on the association between object relations and the alliance.

\section{3: The Current Study}

The current study further examined the relationship between object relations and the alliance using well known measures of both constructs and taking into account therapists' differences. It also explored the influence that timing of the alliance rating and the rating perspective (patient vs. therapist) had on this relationship.

Based on the extant literature, I hypothesized that patients' object relations quality would be positively associated with patient- and therapist-rated alliance. The finding that the relation between the alliance and outcome varies according to the timing of alliance measurement (Horvath \& Bedi, 2002; Horvath \& Symonds, 1991) suggests that such timing could affect the relationship between the alliance and object relations (thus, this was an exploratory question in the current study). Finally, because previous studies had found mixed findings about the role of rating perspective (patient vs. therapist), this study 
continued to explore if rating perspective moderated the relationship between object relations and alliance. 


\section{CHAPTER 2}

\section{METHODOLOGY}

\section{1: Participants}

Participants consisted of 73 patients and 23 therapists from two mental health clinics in the state of Massachusetts. These clinics share many important characteristics. Both sites (a) offer outpatient psychotherapy to both the university population and the surrounding community; (b) offer affordable fees allowing patients of different socioeconomic status to receive services; (c) are training clinics that employ graduate students as clinicians, who work under supervision; and (d) allow flexibility in the type and length of therapy provided (i.e., therapy is neither manualized nor time-restricted).

Therapists invited to participate were in training and actively seeing patients during the study period. Patients invited to participate were all adults (age 18 and over) who started therapy with a new therapist in one of the clinics during the study period. At clinic 1 , only new patients were invited to participate in the study. At clinic 2, new patients and newly transferred (to a new therapist within the same clinic) patients were invited to participate in the study.

Of the 73 patients, 23 were treated at clinic 1 and 50 were treated at clinic 2 . At this second clinic, 25 patients were new to the clinic and 25 patients were newly transferred. Women represented $64.38 \%$ of the total sample and $78.08 \%$ were Caucasian. The average age was 27.53 years $(S D=7.78$ years $)$ and the average family income was $\$ 38,066(S D=\$ 42,090)$. Regarding global symptom severity, the average score on the Diagnostic and Statistical Manual of Mental Disorders, Fourth Edition, Text Revision (DSM-IV-TR; American Psychiatric Association, 2000) Global Assessment of 
Functioning (GAF; see below for full description) was $62.10(S D=6.36)$, corresponding to the lower quartile of the mild symptomatology range. In relation to patients' DSM-IVTR Axis I and Axis II diagnoses, 59\% of patients met criteria for a mood disorder, $42 \%$ for an anxiety disorder, $11 \%$ for an adjustment disorder, $11 \%$ for a substance abuse disorder, $9 \%$ for an eating disorder, $5 \%$ for a disorder usually diagnosed in childhood or adolescence, $5 \%$ for a $\mathrm{V}$-code diagnosis, $3 \%$ for a somatoform disorder, $5 \%$ for a personality disorder, and 3\% for a sexual and gender identity disorder. Five percent of patients did not meet criteria for any DSM-IV-TR disorder and 59\% met criteria for two or more diagnoses. Diagnoses of disorders in full remission, rule-out diagnoses, and diagnoses of nicotine dependence were excluded from these percentages. Table 1 shows patients' characteristics by clinic and combined. $T$-tests revealed no significant differences between clinics on any of these variables.

The 23 therapists were mostly women (55.8\%) and Caucasian (54\%), with a mean age of 30.8 years $(S D=4.33$ years). Twenty therapists were enrolled in a clinical doctoral program and three were studying social work. At the beginning of the study, therapists had been in clinical training for an average of 2.74 years ( $S D=2.04$ years). $T$-tests revealed no significant differences between therapists' demographic characteristics and training experience ${ }^{1}$ as a function of their clinic association. However, a significant difference was found in their primary theoretical orientation. Compared with clinic 2 , therapists at clinic 1 reported that their therapeutic practice was guided significantly more by cognitive theory (diff $=1.12, t(18) 2.46, p=.02)$ and significantly less by psychodynamic theory $(\operatorname{diff}=-2.96, t(18)-4.52, p<.001)$.

\footnotetext{
${ }^{1}$ It was not always possible to collect therapists' data at the time therapists started participating in the study. When this was the case, data available closest to the study start date were used.
} 


\section{2: Measures}

\subsection{1: Demographic Information}

Patients' demographic information, including gender, ethnicity, age, and income, was collected using the Treatment Outcome Package (TOP) Consumer Registration Form (CRF) - version 4.2 (Behavioral Health Laboratories, Inc., 2007), which was part of a battery of measures routinely collected at both clinics. Because the sample was small, ethnicity was recoded into a categorical variable $(0=$ non ethnic minority, $1=$ ethnic minority).

\subsection{2: Symptom Severity}

Patients' symptom severity at baseline was assessed using the DSM-IV-TR GAF score found in the patients' clinical file. GAF scores can range from 0 to 100, with higher scores reflecting less severe symptomatology and a higher level of functioning. The two clinics used different procedures for making $D S M-I V$-TR diagnoses. Clinic 1 administers The Structured Clinical Interview for DSM-IV-TR Axis I Disorders - Clinician Version (SCID-I-CV; First, Spitzer, Gibbon, \& Williams, 1997) and the International Personality Disorder Examination (IPDE; Loranger, 1999). These structured interviews take place at intake and are conducted by a graduate clinician who typically is not assigned to be the treating therapist. A licensed psychologist supervises the intake process. At Clinic 2, the therapist assigns $D S M-I V$-TR diagnoses after one to three intake sessions. A psychologist, social worker, and psychiatrist supervise this diagnostic protocol. Because participants at Clinic 2 included transfer patients who did not receive a new diagnosis when they were transferred, their GAF score was taken from the transfer summary of the previous therapist. The specific clinic where the therapy took place, and whether the patient was 
new to the clinic or a transfer patient, were taken into account in the statistical analyses. Site $($ clinic $1=0$, clinic $2=1)$ and transfer status (new patient $=0$, transfer patient $=1)$ were entered as covariates in the primary analyses.

\subsection{3: Object Relations}

Patients' object relations were measured using Form O of the BORRTI (Bell, 1995), a self-report inventory consisting of 45 descriptive statements that the subject endorses as "true" or "false" according to his or her "most recent experience." The BORRTI yields T-scores of four object relations subscales' (Alienation, Insecure Attachment, Egocentricity, and Social Incompetence), for which higher scores reflect greater object relations' difficulties. Factor analysis has revealed that each subscale is a distinct dimension of object relations (Bell, 1995). Furthermore, the BORRTI has been shown to possess adequate psychometric properties. According to Bell (1995), Cronbach's alpha and Spearman split-half reliability were found to be in the good to excellent range for all object relations subscales, indicating that the items in each scale are closely related to their assigned factor. Bell also reported high factorial stability for these four subscales, with internal consistencies ranging from .78 to .90 . For the current study, a general object relations score was also calculated by averaging the four object relations' dimensions, with higher scores reflecting higher global deficiencies in object relations.

\subsection{4: Therapeutic Alliance}

The short form of the WAI (Hatcher \& Gillaspy, 2006; Horvath \& Greenberg, 1989; Tracey \& Kokotovic, 1989) was used to assess the quality of the therapeutic alliance from both patients' and therapists' perspective. This pantheoretical instrument is 
comprised of 12 items rated on a 7-point scale from 1 ("never") to 7 ("always") that assess Bordin's (1979) proposed dimensions of the alliance: agreement on therapy goals, agreement on therapy tasks, and the patient-therapist bond. The WAI is one of the most frequently used alliance measures, and has demonstrated good psychometric properties (Horvath \& Greenberg, 1989; Tracey \& Kokotovic, 1989). Based on item homogeneity indexes, the patient version of the WAI yielded a Cronbach alpha reliability estimate of .93 , and the therapist version yielded a reliability estimate of .87 (Horvath \& Greenberg, 1989). The WAI appears to be a valid scale to measure one general alliance factor, as well as the three specific alliance subscales of goal, task, and bond (Tracey \& Kokotovic, 1989). Given that several studies have demonstrated high correlations among the WAI subscales (e.g., Klein et al., 2003) and that the subscales do not necessarily predict improvement beyond the global alliance factor (e.g., Hatcher \& Barends, 1996), the total scores from the patient and therapist versions were used in the present analyses. Higher scores reflect better alliances (possible range of 12 to 84 ).

\section{3: Procedure}

Potential participants reviewed and signed a consent form and received information about confidentiality before any data were collected. Once they provided written consent, participants completed the BORRTI at baseline. Patients also completed the TOP-CRF as part of the clinics' intake protocol. WAI data were collected from therapists and patients approximately after sessions $1,3,7,15$, and $30^{2}$. Patients who entered the study close to the end of the study's data collection period only completed the WAI at earlier sessions. On average, patients had 6.40 sessions ( $S D=7.99$ sessions $)$

\footnotetext{
${ }^{2}$ In some cases, data were missing because the research subject did not have time that day or research personnel was not available to administer the data collection.
} 
during the study period. One patient finished treatment before the study ended. All participants were offered a small gift as compensation after completing the baseline object relations' measure. For the current study, all relevant data were stored in a database where participants were identified only by a number in order to guarantee confidentiality. Data collection was approved by the review boards of the two universities where the clinics are located.

\section{4: Analytic Strategy}

Variable distributions and descriptive statistics were first examined in order to identify skewed distributions and univariate outliers. Univariate outliers, with z-scores larger than \pm 3.29 , were transformed by replacing their raw score value with the next highest or lowest value as recommended by Tabachnick and Fidell (2001). Missing data were imputed through a single deterministic imputation in STATA (StataCorp, 2007). No data were imputed for completely missed data collection sessions.

Hierarchical Linear Modeling (HLM; Raudenbush \& Bryk, 1992) was used to analyze the relationship between object relations and the therapeutic alliance, controlling for patient demographic variables, symptom severity, transfer status, therapist differences, and clinic. The advantage of using HLM is that it extends multiple regression analyses for different levels of data, making it suitable for nested data. In this study, sessions at level 1 were nested within patients at level 2, who were nested within therapists at level 3 (see Figure 1). Having therapists at level 3 allowed controlling for potential differences between therapists (e.g., different personalities, different theoretical orientations, and different therapeutic styles). Even though this study did not have enough power to include specific therapist characteristics at level 3, it accounted for their 
unobserved variance. This would not be possible with a one level multiple regression given that it would not take into account that there are different therapists, and that several patients share the same therapist.

According to Tasca and Gallop (2009), HLMs have many advantages, such as allowing to model change even if data is missing at level 1, modeling nonlinear change in individuals, and not requiring data to meet sphericity assumptions. This allows analysis of data when not all individuals have the same number of waves of data (individuals can be included with as little as one wave of data) and when the time between data collection varies between individuals. Because WAI data were not always collected in the exact session it was planned, the actual session data collection occasion was included in the model as a predictor (time).

Following Singer and Willett's (2003) suggestion, HLMs were developed in a sequence of models built from simpler to more complex. The models for general object relations predicting patient-rated alliance, object relations' dimensions predicting patientrated alliance, general object relations predicting therapist-rated alliance, and object relations' dimensions predicting therapist-rated alliance were constructed in the following order: (1) Base Models, including the alliance as outcome, with no predictors at any level; (2) Conditional Intercept Models, including alliance as outcome and object relations (general score or dimensional scores) as level 2 predictors; (3) Unconditional Linear, Quadratic, and Cubic Models, including alliance as outcome and time as a level 1 predictor. Because the linear, quadratic, and cubic effect of time were not significant for patient-rated alliance models, these predictors were dropped. Only the linear effect of time was kept in the therapist-rated alliance models because the quadratic and cubic 
effects were not significant. To test whether time moderates the relationship between object relations and the alliance, the interaction of object relations and linear time (Object Relations*Time) was added to the general object relations models by including at level 2 object relations as a predictor of the level 1 time coefficient. This cross-level interaction was dropped because it was not significant in either general object relations model; (4) Conditional Linear Models, including time as a level 1 predictor (for therapist-rated alliance models, but not for patient-rated alliance models), object relations (general score or dimensional scores), patient control variables (GAF score, age, transfer status, family income, gender, and ethnic minority status) as level 2 predictors, and clinic as a level 3 control variable (for therapist-rated alliance models, but not for patient-rated alliance models because there was no significant variance in alliance at level 3). Only significant control variables were included in the final models (family income for general object relations predicting patient-rated alliance, GAF score for general object relations predicting therapist-rated alliance, and GAF score for object relations' dimensions predicting therapist-rated alliance; Transfer status and clinic, as well as other control variables, were dropped because they were not significant predictors of the alliance). Four final models were constructed:

(1) Object relations general score predicting patient-rated alliance:

Level 1 model: $\mathrm{Y}=\mathrm{P} 0+\mathrm{E}$

Level 2 model: P0 = B00 + B01*(Income $)+$ B02*(General Obj. Rel. $)+$ R0

Level 3 model: $\mathrm{B} 00=\mathrm{G} 000+\mathrm{U} 00$

$$
\begin{aligned}
& \mathrm{B} 01=\mathrm{G} 010 \\
& \mathrm{~B} 02=\mathrm{G} 020
\end{aligned}
$$


Where $\mathrm{Y}$ is the patient-rated alliance outcome; $\mathrm{P} 0$ is the alliance average for sessions; E is the unexplained alliance variability between sessions; B00 is the alliance average for patients; B01 is the average effect of income across patients; B02 is the average effect of general object relations across patients; $\mathrm{R} 0$ is the unexplained alliance variability between patients; G000 is the alliance average for therapists; U00 is the unexplained alliance variability between therapists; G010 is the average effect of patient income across therapists; and G020 is the average effect of patient general object relations across therapists.

(2) Object relations dimensional scores predicting patient-rated alliance:

Level 1 model: $\mathrm{Y}=\mathrm{P} 0+\mathrm{E}$

Level 2 model: $\mathrm{P} 0=\mathrm{B} 00+\mathrm{B} 01 *($ Alienation $)+\mathrm{B} 02 *($ Insecure Attachment $)+$ $\mathrm{B} 03 *($ Egocentricity $)+\mathrm{B} 04 *($ Social Incompetence $)+\mathrm{R} 0$

Level 3 model: $\mathrm{B} 00=\mathrm{G} 000+\mathrm{U} 00$

$$
\begin{aligned}
& \mathrm{B} 01=\mathrm{G} 010 \\
& \mathrm{~B} 02=\mathrm{G} 020 \\
& \mathrm{~B} 03=\mathrm{G} 030 \\
& \mathrm{~B} 04=\mathrm{G} 040
\end{aligned}
$$

Where $\mathrm{Y}$ is the patient-rated alliance outcome; $\mathrm{P} 0$ is the alliance average for sessions; E is the unexplained alliance variability between sessions; B00 is the alliance average for patients; $\mathrm{B} 01$ is the average effect of alienation across patients; $\mathrm{B} 02$ is the average effect of insecure attachment across patients; B03 is the average effect of egocentricity across patients; B04 is the average effect of social incompetence across patients; R0 is the unexplained alliance variability between patients; G000 is the alliance 
average for therapists; U00 is the unexplained alliance variability between therapists; G010 is the average effect of alienation across therapists; G020 is the average effect of insecure attachment across therapists; G030 is the average effect of egocentricity across therapists; and G040 is the average effect of social incompetence across therapists.

(3) Object relations general score predicting therapist-rated alliance:

Level 1 model: $\mathrm{Y}=\mathrm{P} 0+\mathrm{P} 1 *($ Time $)+\mathrm{E}$

Level 2 model: $\mathrm{P} 0=\mathrm{B} 00+\mathrm{B} 01 *(\mathrm{GAF})+\mathrm{B} 02 *($ General Obj. Rel. $)+\mathrm{R} 0$

$$
\mathrm{P} 1=\mathrm{B} 10
$$

Level 3 model: $\mathrm{B} 00=\mathrm{G} 000+\mathrm{U} 00$

$$
\begin{aligned}
& \mathrm{B} 01=\mathrm{G} 010 \\
& \mathrm{~B} 02=\mathrm{G} 020 \\
& \mathrm{~B} 10=\mathrm{G} 100
\end{aligned}
$$

Where $\mathrm{Y}$ is the therapist-rated alliance outcome; $\mathrm{P} 0$ is the alliance average for sessions; P1 is the average effect of time across session; $\mathrm{E}$ is the unexplained alliance variability between sessions; B00 is the alliance average for patients; B01 is the average effect of symptom severity (GAF) across patients; B02 is the average effect of general object relations across patients; $\mathrm{R} 0$ is the unexplained alliance variability between patients; B10 is the average effect of time across patients; G000 is the alliance average for therapists; U00 is the unexplained alliance variability between therapists; G010 is the average effect of patient symptom severity (GAF) across therapists; G020 is the average effect of patient general object relations across therapists; and G100 is the average effect of time across therapists. 
(4) Object relations dimensional scores predicting therapist-rated alliance:

Level 1 model: $\mathrm{Y}=\mathrm{P} 0+\mathrm{P} 1 *($ Time $)+\mathrm{E}$

Level 2 model: $\mathrm{P} 0=\mathrm{B} 00+\mathrm{B} 01 *(\mathrm{GAF})+\mathrm{B} 02 *($ Alienation $)+\mathrm{B} 03 *($ Insecure

$$
\begin{aligned}
& \text { Attachment })+ \text { B04* (Egocentricity })+ \text { B } 05 *(\text { Social } \\
& \text { Incompetence })+ \text { R0 } \\
& \text { P1 = B } 10
\end{aligned}
$$

Level 3 model: $\mathrm{B} 00=\mathrm{G} 000+\mathrm{U} 00$

$$
\begin{aligned}
& \mathrm{B} 01=\mathrm{G} 010 \\
& \mathrm{~B} 02=\mathrm{G} 020 \\
& \mathrm{~B} 03=\mathrm{G} 030 \\
& \mathrm{~B} 04=\mathrm{G} 040 \\
& \mathrm{~B} 05=\mathrm{G} 050 \\
& \mathrm{~B} 10=\mathrm{G} 100
\end{aligned}
$$

Where $\mathrm{Y}$ is the therapist-rated alliance outcome; $\mathrm{P} 0$ is the alliance average for sessions; P1 is the effect of time across sessions; E is the unexplained alliance variability between sessions; B00 is the alliance average for patients; B01 is the average effect of symptom severity (GAF) across patients; B02 is the average effect of alienation across patients; B03 is the average effect of insecure attachment across patients; B04 is the average effect of egocentricity across patients; B05 is the average effect of social incompetence across patients; R0 is the unexplained alliance variability between patients; B10 is the average effect of time across patients; G000 is the alliance average for therapists; U00 is the unexplained alliance variability between therapists; G010 is the average effect of patient symptom severity across therapists; G020 is the average effect 
of alienation across therapists; G030 is the average effect of insecure attachment across therapists; G040 is the average effect of egocentricity across therapists; G050 is the average effect of social incompetence across therapists; and G100 is the average effect of time across therapists.

In the four models, all continuous variables, including time, were grand mean centered, in order for coefficients to reflect the predicted score for someone with a mean score at the average session when data was collected (session 5). All categorical variables remained uncentered. 


\section{CHAPTER 3}

\section{RESULTS}

Descriptive statistics for study variables at each level are presented in Table 2.

\subsection{Patients' and Therapists' Alliance Perception}

The correlation between patient and therapist alliance ratings was small, but significant $(r=0.24, p=.05)$. Considering average alliance perspectives across time for each dyad $(N=73)$, patients' alliance ratings were significantly higher than therapists' ratings alliance by an average of 4.54 points ( $\operatorname{diff}=4.54, t(72) 4.23, p<.001)$.

\subsection{Predicting Patients' Alliance with General Object Relations}

See Table 3 for the results pertaining to predicting patients' alliance from general object relations. The baseline model shows that patient-rated alliance was significantly different from 0 (g000 60.97, $t(22) 68.89, p<.001)$, with patients reporting strong alliances. This model also revealed that $32.79 \%$ of the variance in patient-rated alliance was at level 1 (between sessions), 64.76\% at level 2 (between patients), and $2.45 \%$ at level 3 (between therapists). Although the variance at the patient level was significant (ro $\left.37.57, X^{2}(50) 282.74, p<.001\right)$, the variance at the therapist level was not (u00 1.42, $X^{2}$ (22) $29.40, p=.13$ ). Thus, later models tried to predict level 1 and 2 variability, but not

level 3. The conditional intercept model revealed that general object relations marginally predicted patient-rated alliance $\left(\mathrm{g}_{010}-0.15, t(71)-1.99, p=.05\right)$. Patients' object relation deficits were associated with worse alliance perception. The unconditional linear (g100 0.01, $t(136) 0.180, p=.89)$, quadratic (g200, $-0.01, t(135)-0.811, p=.42)$, and cubic models (g300, 0.0004, $t(134) 0.391, p=.70)$ revealed that time (session when alliance was measured) did not significantly predict patient-rated alliance. In addition, time did not 
significantly moderate the relationship between object relations and patient-rated alliance $(\mathrm{g} 110,0.01, t(134) 1.52, p=.13)$; thus, the cross-level interaction Time*Object Relations was dropped. The conditional model with controls revealed that no controls were significant when entered together. Adding the controls one by one into the model revealed that family income was significant, and was kept as a level 2 predictor. The conditional trimmed model showed that patients' object relations predicted patient-rated alliance (g020 $-0.16, t(70)-2.02, p=.047)$, controlling for family income. This final model explained $14.91 \%$ of the variance in patient-rated alliance at the patient level (level 2).

\subsection{Predicting Patients' Alliance with Object Relations' Dimensions}

See Table 4 for the results pertaining to predicting patients' alliance from object relations' dimensions. The baseline model, and the unconditional linear, quadratic, and cubic models are the same as in the models predicting patient-rated alliance with general object relations. The conditional intercept model showed that alienation, insecure attachment, and egocentricity significantly predicted patient-rated alliance. Higher alienation scores (g010 - $0.34, t(68)-2.28, p=.03$ ) and higher insecure attachment T-scores (g020 - $0.20, t(68)-2.55, p=.01)$ were associated with a more negative patient-rated alliance. On the other hand, higher egocentricity scores were associated with a more positive patient-rated alliance ( $\mathrm{g}_{030} 0.42, t(68) 2.38, p=.02$ ). Social incompetence did not significantly predict patient-rated alliance $\left(\mathrm{g}_{040} 0.14, t(68) 1.31, p=.20\right)$. The conditional model with controls revealed that no controls were significant when entered together or one by one. Thus, the trimmed model was equivalent to the conditional intercept model. This model explained $9.85 \%$ of patient alliance variance at the patient level (level 2). 


\subsection{Predicting Therapists' Alliance with General Object Relations}

See Table 5 for the results pertaining to predicting therapists' alliance from general object relations. The baseline model showed that therapists' alliance perception was significantly different from 0 (g000 57.57, $t(22) 44.85, p<.001$ ), with therapists' reporting moderately strong alliances. This model revealed that $37.01 \%$ of the variance in therapists' alliance perception was at level 1 (between sessions), $10.05 \%$ at level 2 (between patients), and 52.94\% at level 3 (between therapists). Variance was significant at the patient (ro 5.55, $\left.X^{2}(50) 98.19, p<.001\right)$ and therapist level (u00 29.25, $X^{2}(22)$ 170.43, $p<.001)$. Thus, later models tried to predict level 1, 2, and 3 variability. The conditional intercept model showed that patients' general object relations did not significantly predict therapists' alliance perception (g010 $0.02, t(71) 0.27, p=.79)$. The unconditional linear model revealed that time significantly predicted therapists' alliance perception ( $\left.\mathrm{g}_{100} 0.21, t(136) 2.95, p<.01\right)$, and was kept in the model. On average, having more sessions was associated with a more positive therapist-rated alliance. The unconditional quadratic (g200 -0.01, $t(135)-1.14, p=.26)$ and cubic models (g300 -0.001, $t(134)-0.43, p=.67)$ revealed no significant quadratic or cubic effect of time. The conditional model with controls showed that patients' GAF significantly predicted therapist-rated alliance ( $\left.\mathrm{g}_{010} 0.27, t(65) 3.94, p<.001\right)$. On average, less severe symptomatology was associated with a more positive therapist-rated alliance. No other controls were significant when entered together or on their own. The conditional trimmed model showed that GAF significantly predicted therapist-rated alliance (g010 0.29, $t(70)$ $4.83, p<.001)$ controlling for time. This model explained $11.71 \%$ of session variance (level 1), 36.22\% of patient variance (level 2), and $9.64 \%$ of therapist variance (level 3). 


\subsection{Predicting Therapists' Alliance with Object Relations' Dimensions}

See Table 6 for the results pertaining to predicting therapists' alliance from object relations' dimensions. The baseline model and the unconditional linear, quadratic, and cubic models are the same as in the models predicting therapist-rated alliance with general object relations. The conditional intercept model showed that alienation (go10 0.07, $t(68) 0.72, p=.48)$, insecure attachment (g020 0.08, $t(68) 1.29, p=.20)$, egocentricity (g030 - $0.16, t(68)-1.84, p=.07)$, and social incompetence (g040 - $0.03, t(68)$ $-.32, p=.75)$ did not significantly predict therapist-rated alliance. The conditional model with controls revealed that patients' GAF significantly predicted therapist-rated alliance (g010 0.26, $t(62) 3.76, p<.001)$. No other controls were significant when entered together or on their own. The conditional trimmed model showed that patients' GAF significantly predicted therapist-rated alliance $\left(\mathrm{g}_{010} 0.27, t(67) 3.96, p<.001\right)$ controlling for time. This final model explained $12.73 \%$ of the variance between sessions (level 1), $33.51 \%$ of the variance between patients (level 2), and $9.50 \%$ of the variance between therapists (level 3). 


\section{CHAPTER 4}

\section{DISCUSSION}

This study examined the relationship between object relations and the alliance, and whether timing of the alliance rating and the rating perspective moderated this relationship. The main findings were as follows: (1) On average, patients perceived the alliance more positively than their therapists, and there was a small correlation between their perspectives (i.e., there was low agreement within the therapeutic dyad about their level of agreement on therapy goals and tasks, and the quality of their bond); (2) Patient general object relation deficits, as well as greater alienation and insecure attachment, were negatively associated with patient-rated alliance; (3) Patient egocentricity was positively associated with patient-rated alliance; (4) Patient object relations (both the generally factor and dimensions) did not significantly predict therapist-rated alliance, but symptom severity did (greater severity was related to worse alliance); (5) Greater number of therapy sessions predicted a more positive therapist-rated alliance, but did not predict patient-rated alliance; (6) Number of sessions did not moderate the relationship between object relations and patient-rated or therapists-rated alliance; (7) Most of the variance in patient-rated alliance was explained by patient variability, while most of the variance in therapist-rated alliance was explained by therapist variability.

The finding that patients perceive the alliance more positively than therapists, and the low agreement between patients and therapists about the quality of the alliance, is consistent with literature reporting significant differences between patient and therapist alliance rating, especially early in treatment (see Horvath \& Bedi, 2002). It seems important to keep in mind in both research and practice that the therapeutic relationship 
involves at least two people who may have a very different experience about their relationship and their work together. As Horvath and Bedi stated, the therapeutic relationship is asymmetrical, with patients and therapists having different responsibilities and phenomenological experiences (e.g., therapists' experience of the relationship is partly contextualized by their clinical experience and theoretical perspective). Patients' therapeutic experience is construed in light of past relationships (Horvath \& Bedi, 2002), and there is no reason to think that this does not hold true for therapists as well.

As hypothesized, patients' general object relations deficits, as well as greater alienation and insecure attachment, predicted worse patient alliance perception. Because healthy object relations involve the capacity to establish and maintain a sense of separateness between self and other, consistent emotional relationships, and cohesive and stable representations of oneself, it is not surprising that patients' object relations predicted how patients perceived the relationship with their therapists. These findings are consistent with Bell's (1995) description of patients with high alienation experiencing lack of trust in relationships and having difficulties with intimacy, and patients with high insecure attachment T-scores being extremely sensitive to rejection, concerned about being liked and accepted by others, and fearing abandonment.

On the other hand, contrary to this study's hypothesis, greater egocentricity was associated with a more positive patient alliance perception. This finding is surprising considering Bell's (1995) description of patients with high egocentricity as mistrusting others' motivations and having a tendency to feel humiliated and defeated by others. It is possible that because of their egocentricity these patients tend to have a more positive 
perception of their own ability to establish positive relationships, and of how others perceive them.

Social incompetence did not significantly predict patient- or therapist-rated alliance. It might be that although less socially competent patients tend to have more difficulty establishing satisfactory relationships, this may be counterbalanced by their greater appreciation of the relationship they do establish with the therapist. These patients may also be more protective of the relationship with their therapist and, thus, avoid reporting anything negative about it. It is important to note that, on average, patients' egocentricity and social incompetence T-scores were lower than their alienation and insecure attachment T-scores. Less range in egocentricity and social incompetence scores may partly explain why alienation and insecure attachment significantly predicted the alliance in a negative direction, while the former did not.

The finding that quality of patients' object relations predicted patients' alliance perception is consistent with previous literature reporting that intrapsychic and interpersonal patient characteristics are associated with the alliance (Constantino et al., 2002; Constantino et al., in press). The present results support previous findings of a significant relationship between patient object relations and patients' alliance perception (e.g. Pinsker-Aspen et al., 2007; Piper et al., 1991), and are inconsistent with studies that failed to find a significant relationship (Goldman \& Anderson, 2007; Van et al. 2008). In the case of Goldman and Anderson's study, most of their effects, although insignificant, are in the same direction as this study's effects. It seems that their small sample size ( $N=$ 30) may explain why they did not find a significant relationship between patients' alliance perception and object relations. In the case of Van et al.'s study, it is difficult to 
compare their results with this study's results because their sample only included patients' diagnosed with depression and the measures used were different. It should also be noted that the current findings are consistent with studies reporting that patients' global interpersonal problems, resistance, coldness, hostility, defensiveness, negativistic thinking, and attachment pattern predict alliance quality (Constantino et al., 2002; Constantino et al., in press; Parish \& Eagle, 2003).

Counter to this study's hypothesis, patients' general object relations, as well as patients' alienation, insecure attachment, egocentricity, and social incompetence, did not significantly predict therapists' alliance perception. These findings differ from several previous studies (Dyke, 1996; Niemeyer, 2005; Piper et al., 1991). Unfortunately, it is difficult to compare the results of these studies because of the dissimilarities in the measures used. The fact that patient object relation quality did not predict therapist perception of the alliance in this sample could also be a function of the current study including only therapists with little clinical experience. It is possible that these novice therapists were less perceptive of patients' variation in relational difficulties and struggles with the therapeutic relationship, which would be consistent with Mallinckrodt and Nelson's (1991) finding that novice therapists are less skilled at identifying poor or deteriorating alliances.

The fact that patients' object relations predicted patient-rated, but not therapistrated, alliance suggests that who rates the alliance moderates the relationship between object relations and alliance. Nevertheless, it is also possible that this result may partly be explained by shared method variance since object relations was only measured with a patient self-report measure. 
Even though patients' object relations did not predict therapists' alliance perception, symptom severity did. Less severe patient symptomatology was associated with more positive therapist-rated alliance; however, symptom severity did not predict patient-rated alliance. It is possible that therapists working with patients with more severe symptomatology perceive their work as more challenging, feel less competent, and may be concerned about the patients' risks to harm themselves or others. This finding may also be partly explained by a self-fulfilling prophecy, where therapists are biased to perceive patients with more severe symptomatology as more challenging and less gratifying to work with. Unfortunately, because this study did not include an observer perspective, it is not possible to know whether therapists' perception of greater difficulty in the alliance with more severe patients would be evident to an objective rater. Previous research has arrived at mixed results about the relationship between symptom severity and the alliance (Horvath \& Bedi, 2002). These mixed results may be at least partially explained by the finding that alliance rating perspective moderates the relationship between symptom severity and alliance. It is also possible that these results are partly explained by the limited experience of the therapist sample given that therapists early in their career have more difficulties working with severely impaired patients (see Horvath $\&$ Bedi, 2002).

Family income significantly, and positively, predicted patients' perception of the alliance. However, this effect was small and disappeared when the four dimensions of object relations were included in the model. The fact that income was a significant predictor at all was unexpected and could perhaps be studied further. Patients' age, gender, and ethnic minority status did not significantly predict patients' or therapists' 
alliance perception. Whether a patient was a new or a transfer patient did not affect alliance perception of either member of the dyad, making the results of this study generalizable to new and transfer patients, which is a strength of this study. Another strength is that the study took place in naturalistic settings with patients receiving treatment-as-usual, allowing greater generalizability and relevance to the practitioner.

Time was a significant predictor of therapist-rated, but not patient-rated, alliance. More number of sessions was associated with a more positive therapist-rated alliance, while patient-rated alliance remained stable across sessions. These results suggest that as the dyad gets to know each other better, therapists tend to have a more positive impression on the level of agreement on the goals and tasks of treatment, and feel a greater emotional bond with their patient. Why isn't the same true for patients? One hypothesis is that because patients' perception of the alliance starts higher, there may a ceiling effect. A second hypothesis is that at the same time that patients' become more comfortable in therapy and get to know the therapist better, they start getting into more difficult psychotherapy material, which could negatively affect their perception of the alliance. A third hypothesis is that therapists expect the alliance to improve as the therapeutic process develops and this biases their increasingly positive perceptions of the relationship. Patients, on the other hand, are likely to be less biased by theory and expectation, thus possibly rendering their perceptions as more stable and accurate. Of course, it remains unclear whether patients' perceptions are "accurate" given that they might have secondary motivations for reporting positive alliances (e.g., social desirability, relationship protection, etc.). 
Time did not moderate the relationship between object relations and patients' or therapists' alliance perspective. In other words, the relationship between alliance and object relations did not change depending on when the alliance was measured. It is important to note that for this study most of the alliance data was collected early in treatment; thus, the results may not be representative of what happens later in treatment.

Recent alliance research has drawn attention to the importance of separating therapist and patient variability in the alliance (Baldwin, Wampold, \& Imel, 2007). The current results suggest that almost two thirds of the variance in patients' alliance perception can be explained by patient-level variability, and almost none by therapistslevel variability. This could suggest that differences between therapists do not contribute much to patients' perception of their work together and that patients' alliance perception is largely determined by their own personality, symptomatology, contextual situation, or other characteristics. This result is consistent with Hoyt's (2002) finding that patient variability in the alliance rating partly represents the raters' tendencies to perceive the therapist in a certain manner, regardless of the therapist's contribution to the relationship. This makes theoretical sense considering that object relations determine the experience of the self in an interpersonal environment (Blatt \& Lerner, 1983; Bowlby, 1988; Jacobson, 1964). This is also consistent with the finding that more than half of the variance in therapists' alliance perspective is at the therapists' level and only about one tenth of the variance is at the patients' level. This could suggest that differences between patients do not contribute much to therapists' perception of their work together and that therapists' perception is largely determined by variability at the therapist level. It seems that both patients' and therapists' alliance perception is mostly dependent on variability at the level 
of the perceiver (i.e., therapists' level or patients' level), rather than the other person in the dyad. Because therapists' characteristics have been found to predict the alliance (Constantino et al., 2002), a strength of the current study is that it controls for variance at the therapist level. Future research could study how therapists' object relations, among other characteristics, predict the alliance.

This study has several limitations. First, measures of the alliance and object relations consisted of self-report, creating a problem of shared method variance. Having two raters of the alliance (patient and therapist) helped to partly address this problem, but it would have been ideal to also have patients and therapists provide information about patients' object relations. Second, the sample size was relatively small (73 patients and 23 therapists), which may have prevented finding significant results for effects that were small, such as the relationship between social incompetence and object relations. Third, most patients had mild to moderate symptomatology, so these finding may not generalize to patients' with more severe symptomatology. Fourth, therapists had limited clinical experience, so the results may not generalize to more experienced therapists.

Despite these limitations, this study has relevant clinical implications. The results suggest that it may be important to consider the quality of object relations for treatment planning given that object relations predict patients' alliance perception and a positive alliance appears essential for positive therapy outcome (Castonguay et al., 2006; Horvath $\&$ Bedi, 2002). For patients who have deficits in object relations, it may be especially important to monitor the alliance and repair alliance ruptures promptly. It may be helpful to discuss openly with patients possible alliance difficulties, even before they emerge, as a way to maintain engagement and to prevent drop out. As proposed by Horvath and Bedi 
(2002), an urgent challenge for therapists is progressively negotiating the quality of the relationship. This is especially relevant considering the low agreement within the therapeutic dyad about their level of agreement on therapy goals and tasks, and the quality of the emotional bond. If therapists just rely on their own perception of the alliance, it is likely that they will miss when a patient is struggling with the therapeutic relationship. Nevertheless, it is probably helpful for therapists to be aware of their reactions toward their patients and their work together, especially when working with patients who present more severe symptomatology.

The finding that symptom severity and object relations are not significantly correlated, and that the former predicts therapists' alliance perception while the later predicts patients' alliance perception, may be important for clinical practice. It seems that in order to predict and promote a positive alliance, knowing about patients' symptomatology may not be enough. The increasing tendency over the last two decades to consider only DSM diagnosis for treatment planning, and only secondarily overall personality functioning, ignores mental complexity and may be a disservice to patients and for the establishment of the alliance (PDM Task Force, 2006). This study shows that specific personality dimensions, such as alienation, insecure attachment, and egocentricity, predict patients' satisfaction with the goals and task of treatment, as well as the emotional bond with the therapist. Because a good therapeutic alliance is essential for a positive treatment outcome, assessing symptom patterns, personality patterns, and related social and emotional capacities, among others, appears to be necessary to plan and perform a helpful therapy (PDM Task Force, 2006). 
Table 1. Patient Demographic Characteristics and Diagnoses

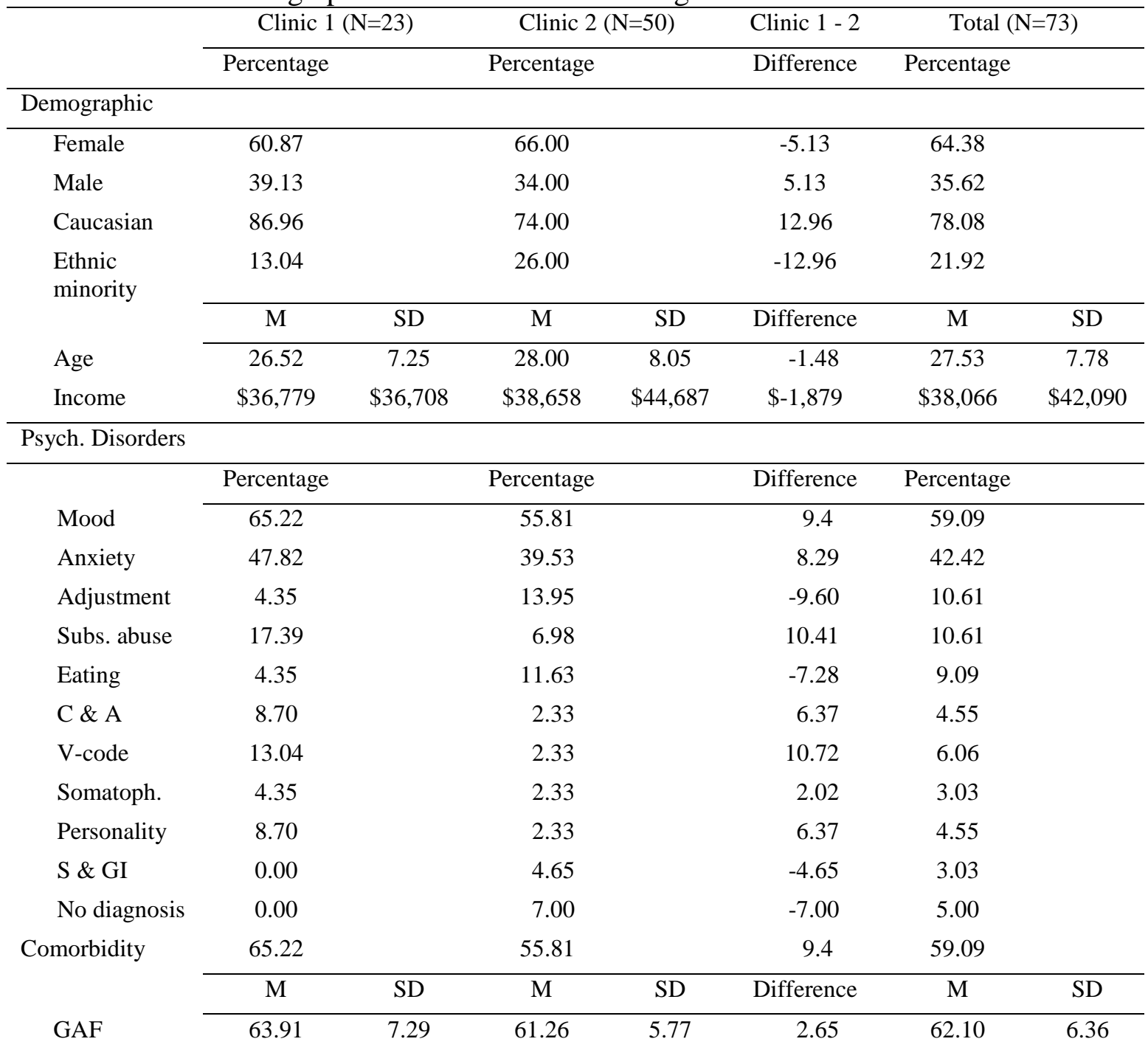

Note. No differences were significant. $\mathrm{C} \& \mathrm{~A}=$ disorder usually diagnosed in childhood or adolescence. S \& GI $=$ sexual and gender identity disorder. 
Table 2. Descriptive Statistics for Study Variables

\begin{tabular}{|c|c|c|c|c|}
\hline Variable Name & $\mathrm{M}$ & SD & Minimum & Maximum \\
\hline \multicolumn{5}{|l|}{ Level $1(\mathrm{~N}=138)$} \\
\hline Alliance Patient & 61.06 & 7.33 & 37.00 & 82.00 \\
\hline Alliance Therapist & 57.17 & 7.73 & 37.00 & 72.00 \\
\hline \multicolumn{5}{|l|}{ Level $2(\mathrm{~N}=73)$} \\
\hline OR & 54.16 & 7.26 & 38.50 & 69.25 \\
\hline Alienation & 56.74 & 9.65 & 37.00 & 76.00 \\
\hline Insecure Attachment & 55.52 & 9.00 & 36.00 & 74.00 \\
\hline Egocentricity & 52.07 & 7.31 & 40.00 & 65.00 \\
\hline Social Incompetence & 52.32 & 8.34 & 41.00 & 71.00 \\
\hline GAF & 62.10 & 6.36 & 50.00 & 80.00 \\
\hline Age & 27.53 & 7.78 & 19.00 & 54.00 \\
\hline Transfer & 0.34 & 0.48 & 0.00 & 1.00 \\
\hline Income & $\$ 38,066$ & $\$ 42,090$ & $\$ 5,000$ & $\$ 187,000$ \\
\hline Male & 0.36 & 0.48 & 0.00 & 1.00 \\
\hline Ethnic minority & 0.22 & 0.42 & 0.00 & 1.00 \\
\hline \multicolumn{5}{|l|}{ Level $3(\mathrm{~N}=23)$} \\
\hline Clinic 2 & 0.30 & 0.47 & 0.00 & 1.00 \\
\hline
\end{tabular}

Note. OR $=$ general object relations score. 
Table 3. Predicting Patients' Alliance with General Object Relations: Unstandarized Coefficients and SEs

\begin{tabular}{|c|c|c|c|c|c|c|c|c|}
\hline Alliance & Model 1 & Model 2 & Model 3 & Model 4 & Model 5 & Model 6 & Model 7 & Model 8 \\
\hline \multirow[t]{2}{*}{ Intercept } & $60.97 * * *$ & $61.07 * * *$ & $60.98 * * *$ & $61.23 * * *$ & $61.39 * * *$ & $60.96 * * *$ & $60.28 * * *$ & $61.10 * * *$ \\
\hline & 0.89 & 0.91 & 0.89 & 0.96 & 1.1 & 0.94 & 1.12 & 0.92 \\
\hline \multicolumn{9}{|l|}{ L1 Predictors } \\
\hline \multirow[t]{2}{*}{ Time } & & & 0.01 & 0.11 & 0.13 & -0.04 & & \\
\hline & & & 0.06 & 0.12 & 0.16 & 0.07 & & \\
\hline \multirow[t]{2}{*}{ Time $^{2}$} & & & & -0.01 & -0.02 & & & \\
\hline & & & & 0.01 & 0.03 & & & \\
\hline \multirow[t]{2}{*}{ Time $^{3}$} & & & & & 0.00 & & & \\
\hline & & & & & 0.00 & & & \\
\hline \multicolumn{9}{|l|}{ L2 predictors } \\
\hline \multirow[t]{2}{*}{ OR } & & $-0.15^{*}$ & & & & -0.13 & -0.11 & $-0.16^{*}$ \\
\hline & & 0.08 & & & & 0.07 & 0.09 & 0.08 \\
\hline \multicolumn{9}{|l|}{ L2 Controls } \\
\hline \multirow[t]{2}{*}{ GAF score } & & & & & & & 0.15 & \\
\hline & & & & & & & 0.11 & \\
\hline \multirow[t]{2}{*}{ Age } & & & & & & & -0.01 & \\
\hline & & & & & & & 0.11 & \\
\hline \multirow[t]{2}{*}{ Transfer } & & & & & & & 0.84 & \\
\hline & & & & & & & 1.57 & \\
\hline \multicolumn{9}{|l|}{$\begin{array}{l}\text { Family } \\
\text { income }\end{array}$} \\
\hline \multirow[t]{2}{*}{$(1,000)$} & & & & & & & 0.03 & $0.03 *$ \\
\hline & & & & & & & 0.00 & 0.00 \\
\hline \multirow[t]{2}{*}{ Male } & & & & & & & 0.43 & \\
\hline & & & & & & & 1.69 & \\
\hline \multirow{3}{*}{$\begin{array}{l}\text { Ethnic } \\
\text { minority }\end{array}$} & & & & & & & & \\
\hline & & & & & & & 1.45 & \\
\hline & & & & & & & 1.94 & \\
\hline \multicolumn{9}{|l|}{$\begin{array}{l}\text { Cross level } \\
\text { interactions }\end{array}$} \\
\hline \multirow[t]{2}{*}{ OR*Time } & & & & & & 0.01 & & \\
\hline & & & & & & 0.01 & & \\
\hline \multicolumn{9}{|l|}{$\begin{array}{l}\text { Variance } \\
\text { components }\end{array}$} \\
\hline \multirow[t]{2}{*}{$\begin{array}{l}\text { Level } 1 \\
\text { variance }\end{array}$} & 19.02 & 19.05 & 19.02 & 19.03 & 19.01 & 18.61 & 19.17 & 19.14 \\
\hline & 4.36 & 4.36 & 4.36 & 4.36 & 4.36 & 4.31 & 4.38 & 4.38 \\
\hline \multirow[t]{2}{*}{$\begin{array}{l}\text { Level } 2 \\
\text { variance }\end{array}$} & $37.57 * * *$ & $35.12 * * *$ & $37.55 * * *$ & $37.28 * * *$ & $37.35 * * *$ & $35.44 * * *$ & $32.24 * * *$ & $31.97 * * *$ \\
\hline & 6.13 & 5.93 & 6.13 & 6.11 & 6.11 & 5.95 & 5.68 & 5.65 \\
\hline \multirow[t]{2}{*}{$\begin{array}{l}\text { Level } 3 \\
\text { variance }\end{array}$} & 1.42 & 2.86 & 1.41 & 1.17 & 1.04 & 2.91 & 1.73 & 3.92 \\
\hline & 1.19 & 1.69 & 1.88 & 1.08 & 1.02 & 1.71 & 1.31 & 1.98 \\
\hline Deviance & 906.47 & 904.87 & 906.45 & 905.8 & 905.65 & 903.41 & 899.6 & 901.79 \\
\hline Parameters & 4 & 5 & 5 & 6 & 7 & 7 & 11 & 6 \\
\hline
\end{tabular}

Note. Model 1 = Base model; Model 2 = Conditional intercept model; Model 3 = Unconditional linear model; Model 4 = Unconditional quadratic model; Model $5=$ Unconditional cubic model; Model $6=$ Conditional Model with cross level interaction; Model $7=$ Conditional model with controls; Model $8=$ Conditional trimmed model (controls that were significant when entered without other controls were kept). Estimation of fixed effects using robust standard errors. OR $=$ general object relations score. $* * * \mathrm{p}<.001, * \mathrm{p}<.05$ 
Table 4. Predicting Patients' Alliance with Object Relations Dimensions: Unstandarized Coefficients and SEs

\begin{tabular}{|c|c|c|c|c|c|c|c|}
\hline Alliance & Model 1 & Model 2 & Model 3 & Model 4 & Model 5 & Model 6 & Model 7 \\
\hline \multirow[t]{2}{*}{ Intercept } & $60.97 * * *$ & $60.99 * * *$ & $60.98 * * *$ & $61.23 * * *$ & $61.39 * * *$ & $60.48 * * *$ & $60.99 * * *$ \\
\hline & 0.89 & 0.80 & 0.89 & 0.96 & 1.10 & 1.03 & 0.80 \\
\hline \multicolumn{8}{|l|}{ L1 Predictors } \\
\hline \multirow[t]{2}{*}{ Time } & & & 0.01 & 0.11 & 0.13 & & \\
\hline & & & 0.06 & 0.12 & 0.16 & & \\
\hline \multirow[t]{2}{*}{ Time $^{2}$} & & & & -0.01 & -0.02 & & \\
\hline & & & & 0.01 & 0.03 & & \\
\hline \multirow[t]{2}{*}{ Time $^{3}$} & & & & & 0.00 & & \\
\hline & & & & & 0.00 & & \\
\hline \multicolumn{8}{|l|}{ L2 predictors } \\
\hline \multirow[t]{2}{*}{ Alienation } & & $-0.34 *$ & & & & -0.26 & $-0.34 *$ \\
\hline & & 0.15 & & & & 0.14 & 0.15 \\
\hline \multirow[t]{2}{*}{ Insecure Attachment } & & $-0.20 *$ & & & & $-0.24 *$ & $-0.20 *$ \\
\hline & & 0.08 & & & & 0.11 & 0.08 \\
\hline \multirow[t]{2}{*}{ Egocentricity } & & $0.42 *$ & & & & $0.40^{*}$ & $0.42 *$ \\
\hline & & 0.18 & & & & 0.18 & 0.18 \\
\hline \multirow[t]{2}{*}{ Social Incompetence } & & 0.14 & & & & 0.14 & 0.14 \\
\hline & & 0.11 & & & & 0.10 & 0.11 \\
\hline \multicolumn{8}{|l|}{ L2 Controls } \\
\hline \multirow[t]{2}{*}{ GAF score } & & & & & & 0.18 & \\
\hline & & & & & & 0.13 & \\
\hline \multirow[t]{2}{*}{ Age } & & & & & & -0.02 & \\
\hline & & & & & & 0.11 & \\
\hline \multirow[t]{2}{*}{ Transfer } & & & & & & 0.91 & \\
\hline & & & & & & 1.54 & \\
\hline \multirow[t]{2}{*}{ Family income } & & & & & & 0.00 & \\
\hline & & & & & & 0.00 & \\
\hline \multirow[t]{2}{*}{ Male } & & & & & & -0.05 & \\
\hline & & & & & & 1.62 & \\
\hline \multirow[t]{2}{*}{ Ethnic minority } & & & & & & 0.92 & \\
\hline & & & & & & 2.13 & \\
\hline \multicolumn{8}{|l|}{ L3 Controls } \\
\hline \multicolumn{8}{|l|}{ Clinic 2} \\
\hline \multicolumn{8}{|l|}{ Variance components } \\
\hline \multirow[t]{2}{*}{ Level 1 variance } & 19.02 & 18.93 & 19.02 & 19.03 & 19.01 & 19.14 & 18.93 \\
\hline & 4.36 & 4.35 & 4.36 & 4.36 & 4.36 & 4.38 & 4.35 \\
\hline \multirow[t]{2}{*}{ Level 2 variance } & $37.57 * * *$ & $33.87 * * *$ & $37.55 * * *$ & $37.28 * * *$ & $37.35 * * *$ & $30.02 * * *$ & $33.87 * * *$ \\
\hline & 6.13 & 5.82 & 6.13 & 6.11 & 6.11 & 5.48 & 5.82 \\
\hline \multirow[t]{2}{*}{ Level 3 variance } & 1.42 & 0.14 & 1.41 & 1.17 & 1.04 & 0.02 & 0.14 \\
\hline & 1.19 & 0.37 & 1.88 & 1.08 & 1.02 & 0.13 & 0.37 \\
\hline Deviance & 906.47 & 898.75 & 906.45 & 905.80 & 905.65 & 893.22 & 898.75 \\
\hline Parameters & 4 & 8 & 5 & 6 & 7 & 14 & 8 \\
\hline
\end{tabular}

Note. Model 1 = Base model; Model 2 = Conditional intercept model; Model 3 = Unconditional linear model; Model 4 = Unconditional quadratic model; Model $5=$ Unconditional cubic model; Model $6=$ Conditional model with controls, Model $7=$ Conditional trimmed model (controls that were significant when entered without other controls were kept). Estimation of fixed effects using robust standard errors. $* * * p<.001, * p<.05$ 
Table 5. Predicting Therapists' Alliance with General Object Relations: Unstandarized Coefficients and SEs

\begin{tabular}{|c|c|c|c|c|c|c|c|c|}
\hline Alliance & Model 1 & Model 2 & Model 3 & Model 4 & Model 5 & Model 6 & Model 7 & Model 8 \\
\hline \multirow[t]{2}{*}{ Intercept } & $57.57 * * *$ & $57.54 * * *$ & $57.54 * * *$ & $57.98 * * *$ & $57.83 * * *$ & $57.39 * * *$ & $58.57 * * *$ & $57.27 * * *$ \\
\hline & 1.28 & 1.28 & 1.25 & 1.31 & 1.38 & 1.28 & 1.40 & 1.20 \\
\hline \multicolumn{9}{|l|}{ L1 Predictors } \\
\hline \multirow[t]{2}{*}{ Time } & & & $0.21 * *$ & 0.39 & 0.37 & 0.17 & $0.20 * *$ & $0.21 * *$ \\
\hline & & & 0.07 & 0.21 & 0.22 & 0.09 & 0.07 & 0.07 \\
\hline \multirow[t]{2}{*}{ Time $^{2}$} & & & & -0.01 & 0.00 & & & \\
\hline & & & & 0.01 & 0.02 & & & \\
\hline \multirow[t]{2}{*}{ Time $^{3}$} & & & & & 0.00 & & & \\
\hline & & & & & 0.00 & & & \\
\hline \multicolumn{9}{|l|}{ L2 predictors } \\
\hline \multirow[t]{2}{*}{ OR } & & 0.02 & & & & 0.04 & 0.01 & 0.07 \\
\hline & & 0.06 & & & & 0.06 & 0.07 & 0.06 \\
\hline \multicolumn{9}{|l|}{ L2 Controls } \\
\hline \multirow[t]{2}{*}{ GAF score } & & & & & & & $0.27 * * *$ & $0.29 * * *$ \\
\hline & & & & & & & 0.07 & 0.06 \\
\hline \multirow[t]{2}{*}{ Age } & & & & & & & 0.13 & \\
\hline & & & & & & & 0.07 & \\
\hline \multirow[t]{2}{*}{ Transfer } & & & & & & & 0.42 & \\
\hline & & & & & & & 1.56 & \\
\hline \multirow[t]{2}{*}{ Family income } & & & & & & & 0.00 & \\
\hline & & & & & & & 0.00 & \\
\hline \multirow[t]{2}{*}{ Male } & & & & & & & -0.48 & \\
\hline & & & & & & & 1.22 & \\
\hline \multirow[t]{2}{*}{ Ethnic minority } & & & & & & & -1.34 & \\
\hline & & & & & & & 1.81 & \\
\hline \multicolumn{9}{|l|}{ L3 Controls } \\
\hline \multirow[t]{2}{*}{ Clinic 2} & & & & & & & -2.51 & \\
\hline & & & & & & & 3.50 & \\
\hline \multicolumn{9}{|l|}{$\begin{array}{l}\text { Cross level } \\
\text { interactions }\end{array}$} \\
\hline \multirow[t]{2}{*}{ OR*Time } & & & & & 0.01 & & & \\
\hline & & & & & & 0.01 & & \\
\hline \multicolumn{9}{|l|}{$\begin{array}{l}\text { Variance } \\
\text { components }\end{array}$} \\
\hline \multirow{2}{*}{$\begin{array}{l}\text { Level } 1 \\
\text { variance }\end{array}$} & 20.45 & 20.41 & 17.86 & 17.76 & 17.69 & 17.37 & 18.03 & 18.05 \\
\hline & 4.52 & 4.52 & 4.23 & 4.21 & 4.21 & 4.17 & 4.25 & 4.25 \\
\hline \multirow[t]{2}{*}{$\begin{array}{l}\text { Level } 2 \\
\text { variance }\end{array}$} & $5.55 * * *$ & 2.38 & $7.32 * * *$ & $6.87 * * *$ & $6.98 * * *$ & $7.79 * * *$ & $1.61 * * *$ & $3.54 * * *$ \\
\hline & 2.36 & $5.64 * * *$ & 2.71 & 2.62 & 2.64 & 2.79 & 1.27 & 1.88 \\
\hline \multirow[t]{2}{*}{$\begin{array}{l}\text { Level } 3 \\
\text { variance }\end{array}$} & $29.25 * * *$ & $29.07 * * *$ & $26.90 * * *$ & $26.47 * * *$ & $26.41 * * *$ & $27.38 * * *$ & $30.58 * * *$ & $26.43 * * *$ \\
\hline & 5.41 & 5.39 & 5.19 & 5.14 & 5.14 & 5.23227 & 5.53 & 5.14 \\
\hline Deviance & 875.08 & 875.05 & 865.05 & 862.83 & 862.73 & 863.9472 & 848.69 & 853.59 \\
\hline Parameters & 4 & 5 & 5 & 6 & 7 & 7 & 13 & 7 \\
\hline
\end{tabular}

Note. Model 1 = Base model; Model 2 = Conditional intercept model; Model 3 = Unconditional linear model; Model 4 = Unconditional quadratic model; Model 5 = Unconditional cubic model; Model $6=$ Conditional Model with cross level interaction; Model $7=$ Conditional model with controls; Model $8=$ Conditional trimmed model (controls that were significant when entered without other controls were kept). Estimation of fixed effects using robust standard errors. OR general object relations score. $* * * \mathrm{p}<.001, * * \mathrm{p}<.01$ 
Table 6. Predicting Therapists' Alliance with Object Relations Dimensions: Unstandarized Coefficients and SEs

\begin{tabular}{|c|c|c|c|c|c|c|c|}
\hline Alliance & Model 1 & Model 2 & Model 3 & Model 4 & Model 5 & Model 6 & Model 7 \\
\hline \multirow[t]{2}{*}{ Intercept } & $57.57 * * *$ & $57.53 * * *$ & $57.54 * * *$ & $57.98 * * *$ & $57.83 * * *$ & $58.54 * * *$ & $57.24 * * *$ \\
\hline & 1.28 & 1.27 & 1.25 & 1.31 & 1.38 & 1.41 & 1.21 \\
\hline \multicolumn{8}{|l|}{ L1 Predictors } \\
\hline \multirow[t]{2}{*}{ Time } & & & $0.21 * *$ & 0.39 & 0.37 & $0.20 * *$ & $0.21 * *$ \\
\hline & & & 0.07 & 0.21 & 0.22 & 0.07 & 0.07 \\
\hline \multirow[t]{2}{*}{ Time $^{2}$} & & & & -0.01 & 0.00 & & \\
\hline & & & & 0.01 & 0.02 & & \\
\hline \multirow[t]{2}{*}{ Time $^{3}$} & & & & & 0.00 & & \\
\hline & & & & & 0.00 & & \\
\hline \multicolumn{8}{|l|}{ L2 predictors } \\
\hline \multirow[t]{2}{*}{ Alienation } & & 0.07 & & & & 0.05 & 0.07 \\
\hline & & 0.10 & & & & 0.10 & 0.09 \\
\hline \multirow[t]{2}{*}{ Insecure Attachment } & & 0.08 & & & & 0.02 & 0.05 \\
\hline & & 0.06 & & & & 0.08 & 0.07 \\
\hline \multirow[t]{2}{*}{ Egocentricity } & & -0.16 & & & & -0.10 & -0.09 \\
\hline & & 0.09 & & & & 0.10 & 0.11 \\
\hline \multirow[t]{2}{*}{ Social Incompetence } & & -0.03 & & & & -0.01 & 0.00 \\
\hline & & 0.10 & & & & 0.09 & 0.10 \\
\hline \multicolumn{8}{|l|}{ Level 2 Controls } \\
\hline \multirow[t]{2}{*}{ GAF score } & & & & & & $0.26 * * *$ & $0.27 * * *$ \\
\hline & & & & & & 0.07 & 0.07 \\
\hline \multirow[t]{2}{*}{ Age } & & & & & & 0.13 & \\
\hline & & & & & & 0.07 & \\
\hline \multirow[t]{2}{*}{ Transfer } & & & & & & 0.43 & \\
\hline & & & & & & 1.56 & \\
\hline \multirow[t]{2}{*}{ Family income } & & & & & & 0.00 & \\
\hline & & & & & & 0.00 & \\
\hline \multirow[t]{2}{*}{ Male } & & & & & & -0.50 & \\
\hline & & & & & & 1.39 & \\
\hline \multirow[t]{2}{*}{ Ethnic minority } & & & & & & -1.35 & \\
\hline & & & & & & 1.87 & \\
\hline \multicolumn{8}{|l|}{ L3 Controls } \\
\hline \multirow[t]{2}{*}{ Clinic 2} & & & & & & -2.48 & \\
\hline & & & & & & 3.52 & \\
\hline \multicolumn{8}{|l|}{ Variance components } \\
\hline \multirow[t]{2}{*}{ Level 1 variance } & 20.45 & 20.39 & 17.86 & 17.76 & 17.69 & 17.80 & 17.85 \\
\hline & 4.52 & 4.52 & 4.23 & 4.21 & 4.21 & 4.22 & 4.22 \\
\hline \multirow[t]{2}{*}{ Level 2 variance } & $5.55 * * *$ & $4.91 * * *$ & $7.32 * * *$ & $6.87 * * *$ & $6.98 * * *$ & $1.81^{* \star *}$ & $3.69 * * *$ \\
\hline & 2.36 & 2.22 & 2.71 & 2.62 & 2.64 & 1.35 & 1.92 \\
\hline \multirow[t]{2}{*}{ Level 3 variance } & $29.25 * * *$ & $30.13 * * *$ & $26.90 * * *$ & $26.47 * * *$ & $26.41 * * *$ & $30.61 * * *$ & $26.47 * * *$ \\
\hline & 5.41 & 5.49 & 5.19 & 5.14 & 5.14 & 5.53 & 5.14 \\
\hline Deviance & 875.08 & 873.36 & 865.05 & 862.83 & 862.73 & 848.11 & 852.90 \\
\hline Parameters & 4 & 8 & 5 & 6 & 7 & 16 & 10 \\
\hline
\end{tabular}

Note. Model 1 = Base model; Model 2 = Conditional intercept model; Model 3 = Unconditional linear model; Model 4 = Unconditional quadratic model; Model $5=$ Unconditional cubic model; Model $6=$ Conditional model with controls, Model $7=$ Conditional trimmed model (controls that were significant when entered without other controls were kept). Estimation of fixed effects using robust standard errors. *** $\mathrm{p}<.001, * * \mathrm{p}<.01$ 
Figure 1. Multilevel Data

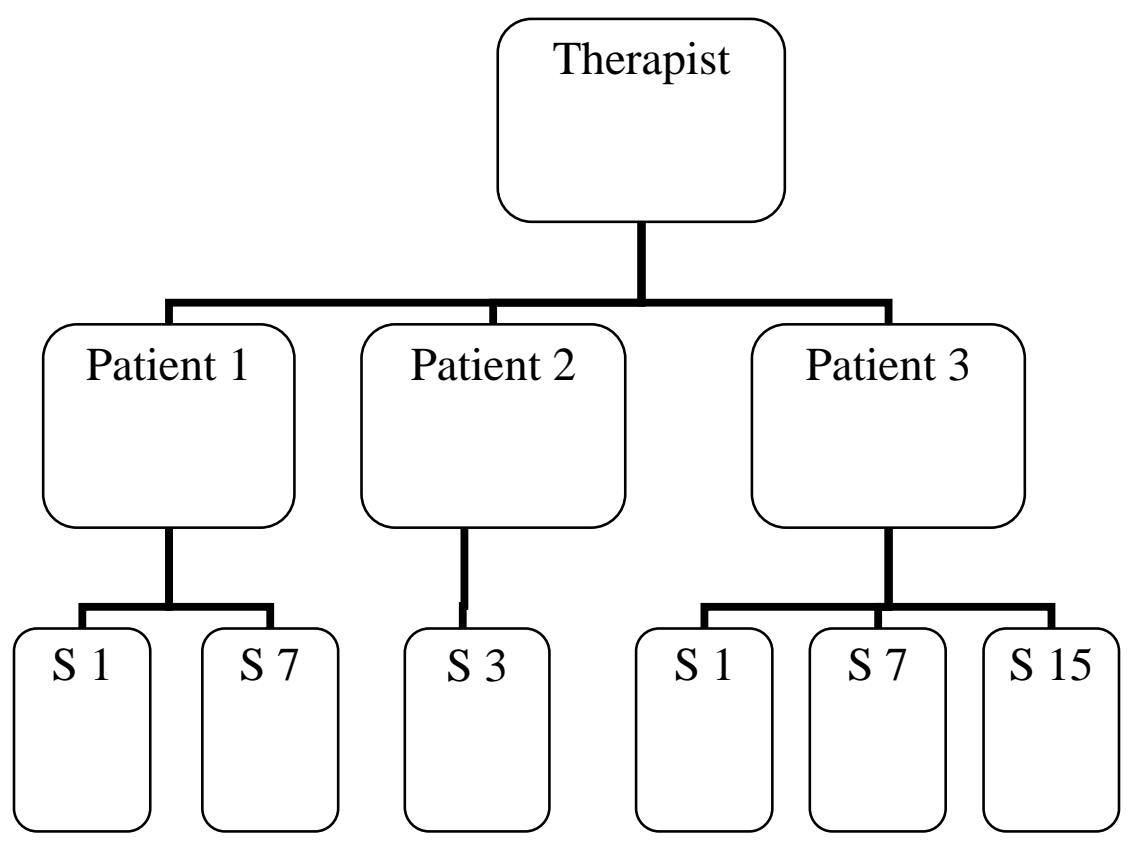




\section{APPENDIX A}

\section{WORKING ALLIANCE INVENTORY (WAI)}

\section{WAI - Patient Version}

On the following page there are some sentences that describe some of the different ways a person might think or feel about his or her therapist. Please complete these ratings in terms of your experience with your therapist during the most recent session. As you read the sentences, mentally insert the name of your therapist in place of the in the text.

\begin{tabular}{ccccccc}
\hline 1 & 2 & 3 & 4 & 5 & 6 & 7 \\
Never & Rarely & Occasionally & Sometimes & Often & Very Often & Always \\
\hline
\end{tabular}

Use the above seven point scale for each item. If the statement describes the way you always feel (or think), circle the number ' 7 '; if it never applies to you, circle the number ' 1 '. Use the numbers in between to describe the variations between these extremes. This questionnaire is confidential; your therapist will not see your answers. Work fast; your first impressions are the ones we would like to see. Please don't forget to respond to every item.

1. improve my situation.

2. What I am doing in therapy gives me new ways of looking at my problem.

3. I believe likes me.

4. does not understand what I am trying to accomplish in therapy.

5. I am confident in 's ability to help me.

6. and I are working on mutually agreed upon goals.

7. I feel that appreciates me.

8. We agree on what is important for me to work on.

9. and I trust one another.

10. and I have different ideas on what my problems are.

11. We have established a good understanding of the kind of changes that would be good for me.

12. I believe the way we are working with my problem is correct. 


\section{WAI - Therapist Version}

On the following pages there are some sentences that describe some of the different ways a person might think or feel about his or her patient. Please complete these ratings in terms of your experience with your patient during the most recent session. As you read the sentences, mentally insert the name of your patient in place of the in the text.

\begin{tabular}{ccccccc}
\hline 1 & 2 & 3 & 4 & 5 & 6 & 7 \\
Never & Rarely & Occasionally & Sometimes & Often & Very Often & Always \\
\hline
\end{tabular}

Use the above seven point scale for each item. If the statement describes the way you always feel (or think), circle the number ' 7 '; if it never applies to you, circle the number ' 1 '. Use the numbers in between to describe the variations between these extremes. Work fast; your first impressions are the ones we would like to see. Please don't forget to respond to every item.

1. and I agree about the things I will need to do in therapy to help improve his/her situation.

2. and I both feel confident about the usefulness of our current activity in therapy.

3. I believe likes me.

4. I have doubts about what we are trying to accomplish in therapy.

5. I am confident in my ability to help

6. We are working on mutually agreed upon goals.

7. I appreciate as a person.

8. We agree on what is important for to work on.

9. and I have built a mutual trust.

10. and I have different ideas on what his/her real problems are.

11. We have established a good understanding between us of the kind of changes that would be good for

12. believes the way we are working with his/her 
APPENDIX B

CONSENT FORMS ${ }^{3}$

Patients' Consent Form

\section{RESEARCH STUDY 984}

\section{CONSENT FOR A RESEARCH STUDY}

University of Massachusetts, Amherst

Title of Project:

Investigators:

The therapeutic relationship between patients and therapists

Paula A. Errazuriz, M.A., M.S.; Michael J. Constantino, Ph.D., \& The

Psychological Services Center

Explanation of Study: The investigators are conducting a study in the Psychological Services Center (PSC) that investigates the therapeutic relationship between patients and therapists. As part of this study, you are being asked to provide information about your perceptions of yourself and others, as well as how you perceive the relationship with your therapist. Some of the materials used for this research are completed as a normal part of treatment in the PSC, while others are unique to this research project. Your decision to participate in this research study will not impact the quality of the clinical care you receive in the PSC nor is it related to whether you can receive services in the PSC.

We are asking you to (1) give the primary researchers access to some information about your treatment, specifically your assessment of the therapeutic relationship, your diagnosis and treatment outcome. These materials will be taken from your clinical file and stripped of any information that can be used to identify you by the Principal Investigator, and then entered into a secure, confidential database. (2) We will also ask you to also complete 2 additional short measures that are pertinent to the current research study. These measures will be used for research only and will not become a part of your clinical file. For the extra time you donate to this project, you will be given the opportunity to select a small "thank you" gift.

All of the information you provide as a patient of the PSC is important and is often used by your therapist to support your treatment. If you agree to participate in this study you will be giving permission to include your treatment data (e.g., assessment of the therapeutic relationship, diagnosis and treatment outcome), in the current research database. Of course, the use of this treatment data does not change any of the procedures used by the PSC for protecting your confidentiality and ensuring that you receive quality care. All other clinical records, such as notes about sessions, treatment reports and videos will not be used for this study and remain a part of your clinical record in the PSC.

If you agree to participate in this research study we will ask you to complete a questionnaire (approximately 10 minutes total) before today's session. Additionally, if you continue to seek services at the PSC, you will be asked to complete 1 short questionnaire (1-3 minutes) after your $4^{\text {th }}$ treatment session. These additional measures ask questions about yourself and others, as well as how you perceive the relationship with your therapist and will always be distinguished from standard clinical paperwork by being printed on pink paper. These additional measures will not be shared with your therapist and are stored only in the research database.

\footnotetext{
${ }^{3}$ Consent forms were slightly different at the two clinics in order adapt to the clinic's context and the Review Board Requirements. The consent forms presented here were used in Clinic 1.
} 
By participating in this study, you will receive a small present (you will be able to choose one of many presents today after completing the questionnaire and open-ended questions).

Your Rights as a Research Participant: Any questions regarding this study should be directed to Paula Errazuriz (perrazur@psych.umass.edu), Dr. Michael Constantino (mconstantino@psych.umass.edu; 413545-1388) or to a member of the PSC office staff who will direct one of the investigators to be in touch with you. If you have any complaints/concerns regarding this study, please contact the human subjects committee at HumanSubjects@ora.umass.edu.

Your participation in this study is entirely voluntary. If you wish to participate in this study, you must sign this form, though you are free to withdraw your consent (including your authorization regarding the use of your clinical information), and to discontinue participation at any time without prejudice to you or effect on your treatment. If you decide to terminate your participation in this study, you should notify Paula Errazuriz (perrazur@psych.umass.edu),Dr. Michael Constantino (mconstantino@psych.umass.edu; 413545-1388) or a member of the PSC office staff who will direct one of the investigators to be in touch with you.

Your participation is also confidential. Only the investigators and PSC staff will be aware that you are participating in this study, and the information used in this research will not include any identifying information about you. Additionally, the results will not be shared with your therapist or any member of the PSC staff. This study involves minimal risks; that is, no risks to your physical or mental health beyond those encountered in the normal course of everyday life.

Statement of Informed Consent to Participate: My signature on this document indicates that I agree to participate in a scientific investigation in the Psychology Department at the University of Massachusetts, Amherst, under the supervision of Dr. Constantino.

The investigation has been explained to me through this document and I understand the explanation. I have been given an opportunity to ask any questions that I may have, and all such questions have been answered to my satisfaction. I understand and agree to the conditions of the study described.

I understand that any information that I provide will remain confidential with respect to my identity. I understand that the services that I receive at the Psychological Service Center will not be affected by my decision to participate, or not participate, in this study. I understand that I will receive a small present for participating in this study, and that I am entitled to no other compensation.

I understand that my participation is voluntary, and that I may withdraw from participating at any time. I am at least 18 years of age and a patient of the Psychological Service Center at the University of Massachusetts, Amherst. I understand that I will receive copy of this consent form.

Participant's Name (printed)

Participant's Signature

Date 


\section{Therapists' Consent Form}

\section{RESEARCH STUDY 984}

\section{CONSENT FOR A RESEARCH STUDY}

University of Massachusetts, Amherst

Title of Project:

Investigators:

The therapeutic relationship between patients and therapists

Paula A. Errazuriz, M.A., M.S.; Michael J. Constantino, Ph.D.

Explanation of Study: This study investigates the therapeutic relationship between patients and therapists. As part of this study, you will be asked to provide information about your perception of yourself and others, as well as how you perceive the relationship with your patients.

We are asking you to (1) give permission to include information about your perception of the alliance with your patients in the research database; and (2) to complete 3 additional short measures.

As part of routine, standard care, therapists in the Psychological Service Center are required to complete an alliance measure after sessions 1, 7, 15, and every 15 sessions until termination. If you give permission to use your alliance data for research purposes, they will be included in the current research database.

If you agree to participate in this research study we will also ask you to complete a questionnaire and two open-ended questions (approximately 15 minutes total), as well as the alliance questionnaire (1-3 minutes) after session 4 for each of your patients. These measures ask you various questions about yourself and others, as well as how you perceive the relationship with your patients.

By participating in this study, you will receive a small "thank you" present (you will be able to choose one of many presents).

Your Rights as a Research Participant: Any questions regarding this study should be directed to Paula Errazuriz (perrazur@psych.umass.edu) or Dr. Michael Constantino (mconstantino@ psych.umass.edu; 413545-1388). If you have any complaints/concerns regarding this study, please contact the human subjects committee at HumanSubjects@ ora.umass.edu.

Your participation in this study is entirely voluntary. If you wish to participate in this study, you must sign this form. If you decide to participate, you are free to withdraw your consent, including your authorization regarding the use of your data, and to discontinue participation at any time without prejudice to you or your patients. If you decide to terminate your participation in this study, you should notify Paula Errazuriz (perrazur@psych.umass.edu) or Dr. Michael Constantino (mconstantino@psych.umass.edu; 413-5451388).

Your participation is also confidential. You will be identified by a number and the investigators will not know your identity. In addition, the investigators will not look at therapists' data until all therapists' data has been collected. The large number of data will prevent the investigators from having any information, such as time in the study when data was collected, that could suggest whose data it is. Additionally, this study involves minimal risks; that is, no risks to your physical or mental health beyond those encountered in the normal course of everyday life. 
Statement of Informed Consent to Participate: My signature on this document indicates that I agree to participate in a scientific investigation in the Psychology Department at the University of Massachusetts, Amherst, under the supervision of Dr. Constantino.

The investigation has been explained to me through this document and I understand the explanation. I have been given an opportunity to ask any questions that I may have, and all such questions have been answered to my satisfaction. I understand and agree to the conditions of the study described.

I understand that any information that I provide will remain confidential with respect to my identity. I understand that I am free to deny any answers to specific questions, at any time, in this study. I understand that I will receive a small present for participating in this study, and that I am entitled to no other compensation.

I understand that my participation is voluntary, and that I may withdraw from participating at any time. I am at least 18 years of age and a therapist of the Psychological Service Center at the University of Massachusetts, Amherst. I understand that I will receive copy of this consent form.

Participant's Name (printed)

Participant's Signature

Date 


\section{REFERENCE LIST}

Abraham, R. E., Van, H. L., Ingenhoven, T. J., Tremonti, W., van Foeken, I., Pieper-de Vries, I., de Groot, J., van't Spijker, A., Spinhoven, P. (2001). The Developmental profile. Journal of Personality Disorders, 15, 457-473.

Ackerman, S. J., \& Hilsenroth, M. J. (2001). A review of therapist characteristics and techniques negatively impacting the therapeutic alliance. Psychotherapy: Theory, Research, Practice, Training, 38, 171-185.

Ackerman, S. J., \& Hilsenroth, M. J. (2003). A review of therapist characteristics and techniques positively impacting the therapeutic alliance. Clinical Psychology Review, 23, 1-33.

American Psychiatric Association. (2000). Diagnostic and statistical manual of mental disorders (4th ed., text revision). Washington, DC: Author.

Baldwin, S. A., Wampold, B. E., \& Imel, Z. E. (2007). Untangling the alliance-outcome correlation: Exploring the relative importance of therapist and patient variability in the alliance. Journal of Consulting and Clinical Psychology, 75, 842-852.

Behavioral Health Laboratories, Inc. (2007). BHL Consumer Registration Form - version 4.2. Marlborough, MA: Behavioral Health Laboratories, Inc.

Bell, M. D. (1991). An introduction to the Bell Object Relations Reality Testing Inventory. Unpublished manuscript, Department of Psychiatry, Veterans Administration Hospital, West Haven, CT.

Bell, M. D. (1995). Bell Object Relations and Reality Testing Inventory (BORRTI) manual. Los Angeles: Western Psychological Services.

Blatt, S. J. (1974). Levels of object representation in anaclitic and introjective depression. The Psychoanalytic study of the child, 29, 7-157.

Blatt, S. J. (1995). Representational structures in psychopathology. In D. Cicchetti, \& S. L. Toth (Eds.), Emotion, cognition, and representation. (pp. 1-33). Rochester, NY: University of Rochester Press.

Blatt, S. J., \& Auerbach, J. S. (2003). Psychodynamic measures of therapeutic change. Psychoanalytic Inquiry, 23, 268-307.

Blatt, S. J., Auerbach, J. S., \& Aryan, M. (1998). Representational structures and the therapeutic process. In R. F. Bornstein, \& J. M. Masling (Eds.), Empirical studies of the therapeutic hour. (pp. 63-107). Washington, DC: American Psychological Association. 
Blatt, S. J., \& Lerner, H. D. (1983). The psychological assessment of object representation. Journal of personality assessment, 47, 7-28.

Bordin, E. S. (1979). The generalizability of the psychoanalytic concept of the working alliance. Psychotherapy: Theory, Research, \& Practice, 16, 252-260.

Bordin, E. S. (1994). Theory and research on the therapeutic working alliance: New directions. In A. O. Horvath, \& L. S. Greenberg (Eds.), The working alliance: Theory, research, and practice (pp. 13-37). Oxford, England: John Wiley \& Sons.

Bowlby, J. (1969). Disruption of affectional bonds and its effects on behavior. Canada's Mental Health Supplement, 59, 12-12.

Bowlby, J. (1988). A secure base. New York: Basic Books.

Castonguay, L. G., Constantino, M. J., \& Holtforth, M. G. (2006). The working alliance: Where are we and where should we go? Theory, Research, Practice, Training, 43, 271-279.

Collins, N. L., \& Read, S. J. (1990). Adult attachment, working models, and relationship quality in dating couples. Journal of personality and social psychology, 58, 644663.

Constantino, M. J., Castonguay, L. G., Zack, S. E., \& DeGeorge, J. (in press). Engagement in psychotherapy: Factors contributing to the facilitation, demise, and restoration of the working alliance. To appear in D. Castro-Blanco, M. S. Karver (Ed). Elusive alliance: Treatment engagement strategies with high-risk adolescents. Washington, D.C.: American Psychological Association Press.

Constantino, M. J., Castonguay, L. G., \& Schut, A. J. (2002). The working alliance: A flagship for the "scientist-practitioner" model in psychotherapy. In G. S. Tryon (Ed.), Counseling based on process research: Applying what we know. (pp. 81-131). Boston: Allyn \& Bacon.

Crits-Christoph, P., \& Connolly Gibbons, M. B. (2003). Research developments on the therapeutic alliance in psychodynamic psychotherapy. Psychoanalytic Inquiry, 23, 332-349.

Dyke, J. T. (1996). The association of attachment, object relations and interpersonal functioning with the working alliance in college counseling. Unpublished doctoral dissertation, Fordham University, NY.

First, M. B., Spitzer, R. L., Gibbon, M., \& Williams, J. B. W. (1997). Structured Clinical Interview for DSM-IV Axis I Disorders - Clinician Version (SCID-CV). Washington, DC: American Psychiatric Press, Inc. 
Freud, S. (1912), The dynamics of transference. Standard Edition. London: Hogarth Press.

Gaston, L. (1990). The concept of the alliance and its role in psychotherapy: Theoretical and empirical considerations. Psychotherapy: Theory, Research, Practice, Training, $27,143-153$.

Geller, J. D., Cooley, R. S., \& Hartley, D. (1982). Images of the psychotherapist: A theoretical and methodological perspective. Imagination, Cognition and Personality, $1,123-146$.

Goldman, G. A., \& Anderson, T. (2007). Quality of object relations and security of attachment as predictors of early therapeutic alliance. Journal of Counseling Psychology, 54, 111-117.

Greenberg, L. S., \& Pinsof, W. M. (1986). Process research: Current trends and future perspectives. In L. S. Greenberg, \& W. M. Pinsof (Eds.), The psychotherapeutic process: A research handbook (pp. 3-20). New York: Guilford Press.

Greenson, R. R. (1965). The working alliance and the transference neuroses. Psychoanalytic Quarterly, 34, 155-179.

Hatcher, R. L. \& Barends A. W. (1996). Patient's view of the alliance in psychotherapy: exploratory factor analysis of three alliance measures. Journal of Consulting and Clinical Psychology, 64, 1326-1336.

Hatcher, R. L., \& Gillaspy, A. (2006). Development and validation of a revised short version of the Working Alliance Inventory. Psychotherapy Research, 16, 12-25.

Hersoug, A. G., Monsen, J. T., Havik, O. E., \& Hoglend, P. (2002). Quality of early working alliance in psychotherapy: Diagnoses, relationship and intrapsychic variables as predictors. Psychotherapy and psychosomatics, 71, 18-27.

Hilliard, R. B., Henry, W. P., \& Strupp, H. H. (2000). An interpersonal model of psychotherapy: Linking patient and therapist developmental history, therapeutic process, and types of outcome. Journal of consulting and clinical psychology, 68, $125-133$.

Honig, M. S., Farber, B. A., \& Geller, J. D. (1997). The relationship of pretreatment representations of mother to early treatment representations of their therapist. Journal of the American Academy of Psychoanalysis \& Dynamic Psychiatry, 25, 357-372.

Horvath, A. O., \& Bedi, R. P. (2002). The alliance. In J. C. Norcross (Ed.), Psychotherapy relationships that work: Therapists contributions and responsiveness to patients (pp. 37-69). New York: Oxford University Press. 
Horvath, A. O., \& Greenberg, L. (1989). Development and validation of the Working Alliance Inventory. Journal of Counselling Psychology, 36, 223-233.

Horvath, A. O., \& Symonds, B. D. (1991). Relation between working alliance and outcome in psychotherapy: A meta-analysis. Journal of Counseling Psychology, 38, 139-49.

Hoyt, W. T. (2002). Bias in participant ratings of psychotherapy process: An initial generalizability study. Journal of Consulting Psychology, 49, 35-46.

Huprich, S. K., \& Greenberg, R. P. (2003). Advances in the assessment of object relations in the 1990s. Clinical psychology review, 23, 665-698.

Jacobson, E. (1964). The self and the object world. Madison, CT: International Universities Press.

Kernberg, O. F. (1976). Object relations theory and clinical psychoanalysis. New York: Jason Aronson, Inc.

Klein, D. N., Schwartz, J. E., Santiago, N. J., Vivian, D., Vocisano, C., Castonguay, L. G. ... Martin, B. (2003). Therapeutic alliance in depression treatment: Controlling for prior change and patient characteristics. Journal of Consulting and Clinical Psychology, 71, 997-1006.

Le Bloc'h, Y., de Roten, Y., Drapeau, M., \& Despland, J. (2006). New, but improved? Comparison between first and revised version of the Helping Alliance questionnaire. Schweizer Archiv für Neurologie und Psychiatrie, 157, 23-28.

Loranger, A. W. (1999). International Personality Disorder Examination: DSM-IV and ICD-10 Interviews. Lutz, FL: Psychological Assessment Resources.

Luborsky, L., McLellan, A. T., Woody, G. E., O’Brien, C. P., Auerbach, A. (1985). Therapist success and its determinants. Archives of General Psychiatry, 42, 602611.

Mallinckrodt, B. \& Nelson, M. L. (1991). Counselor training level and the formation of the psychotherapeutic working alliance. Journal of Consulting Psychology, 38, 133138.

Mallinckrodt, B., Porter, M. J., \& Kivlighan, D. M. J. (2005). Patient attachment to therapist, depth of in-session exploration, and object relations in brief psychotherapy. Psychotherapy: Theory, Research, Practice, Training, 42, 85-100.

Niemeyer, K. M. (2005). An exploration of object relations and the early working alliance in a university clinic sample. Unpublished dissertation, University of North Texas, TX. 
Parish, M., \& Eagle, M. N. (2003). Attachment to the therapist. Psychoanalytic Psychology, 20, 271-286.

PDM Task Force. (2006). Psychodynamic Diagnostic Manual. Silver Spring, MD: Alliance of Psychoanalytic Organizations.

Pinsker-Aspen, J. H., Stein, M. B., \& Hilsenroth, M. J. (2007). Clinical utility of early memories as a predictor of early therapeutic alliance. Psychotherapy: Theory, Research, Practice, Training, 44, 96-109.

Piper, W. E., Azim, H. F., Joyce, A. S., McCallum, M., Nixon, G. W. H, \& Segal, P.S. (1991). Quality of object relations versus interpersonal functioning as predictors of therapeutic alliance and psychotherapy outcome. Journal of Nervous and Mental Disease, 179, 432-438.

Raudenbush, S. W. \& Bryk, A. S. (1992). Hierarchical Linear Models: Applications and Data Analysis Methods. Newbury Park, CA: Sage Publications.

Rogers, C. R. (1957). The necessary and sufficient conditions of therapeutic personality change. Journal of Consulting Psychology, 21, 95-103.

Ryan, E. R., \& Cicchetti, D. V. (1985). Predicting quality of alliance in the initial psychotherapy interview. Journal of Nervous and Mental Disease, 173, 717-725.

Singer, J. D., \& Willett, J. B. (2003). Applied longitudinal data analysis: Modeling change and event occurrence. New York: Oxford University Press.

StataCorp (2007). Stata TM (Version 9.2) [Computer software] College Station, TX: Author.

Tabachnick, B.G., \& Fidell, L.S. (2001). Using Multivariate Statistics (4th Ed.). New York: Harper \& Row.

Tasca, G.A. \& Gallop, R. (2009). Multilevel Modeling of longitudinal data for psychotherapy researchers: I. The basics. Journal of the Society of Psychotherapy Research, 19, 429-437.

Tracey, T. J. \& Kokotovic, A. (1989). Factor structure of the Working Alliance Inventory. Psychological Assessment, 1, 207-210.

Van, H., Hendriksen, M., Schoevers, R., Peen, J., Abraham, R., Dekker, J. (2008). Predictive value of object relations for therapeutic alliance and outcome in psychotherapy for depression: An exploratory study. Journal of nervous and mental disease, 196, 655-662. 
Zetzel, E. (1956). Current concepts of transference. International Journal of PsychoAnalysis, 37, 369-376. 